\title{
Characterization and genetic manipulation of ergot pathway inefficiency in fungi
}

Prashanthi Mulinti

West Virginia University

Follow this and additional works at: https://researchrepository.wvu.edu/etd

\section{Recommended Citation}

Mulinti, Prashanthi, "Characterization and genetic manipulation of ergot pathway inefficiency in fungi" (2011). Graduate Theses, Dissertations, and Problem Reports. 3404.

https://researchrepository.wvu.edu/etd/3404

This Dissertation is protected by copyright and/or related rights. It has been brought to you by the The Research Repository @ WVU with permission from the rights-holder(s). You are free to use this Dissertation in any way that is permitted by the copyright and related rights legislation that applies to your use. For other uses you must obtain permission from the rights-holder(s) directly, unless additional rights are indicated by a Creative Commons license in the record and/ or on the work itself. This Dissertation has been accepted for inclusion in WVU Graduate Theses, Dissertations, and Problem Reports collection by an authorized administrator of The Research Repository @ WVU.

For more information, please contact researchrepository@mail.wvu.edu. 


\title{
Characterization and genetic manipulation of ergot pathway inefficiency in fungi
}

\author{
Prashanthi Mulinti
}

\author{
Dissertation submitted to the \\ Davis College of Agriculture, Forestry, and Consumer Sciences \\ at West Virginia University \\ in partial fulfillment of the requirements \\ for the degree of

\begin{abstract}
Doctor of Philosophy
in

Genetics and Developmental Biology
\end{abstract}

\author{
Daniel G. Panaccione, Ph.D., Chair \\ Jed H. Doelling, Ph.D. \\ Joseph B. Morton, Ph.D. \\ Christopher L. Schardl, Ph.D. \\ Jianbo Yao, Ph.D. \\ Division of Plant and Soil Sciences \\ Morgantown, West Virginia
}

2011

Keywords: Ergot alkaloids, GFP, A. fumigatus, Neotyphodium sp. Lp1, ergot pathway inefficiency, RNA interference (RNAi), overexpression

Copyright 2011 Prashanthi Mulinti 


\title{
ABSTRACT
}

\section{Characterization and genetic manipulation of ergot pathway inefficiency in fungi}

\author{
Prashanthi Mulinti
}

Ergot alkaloids are mycotoxins that negatively affect humans and animals but also have useful pharmaceutical properties. Ergot alkaloids have been extensively studied in Claviceps purpurea, and also have been reported in other fungi, such as certain Penicillium spp., Aspergillus fumigatus, and several Neotyphodium spp. that are endophytes of grasses. There is a high degree of variation in the production of ergot alkaloids within an individual species and among producers from different taxa, which means different fungi accumulate different profiles of ergot alkaloids rather than a single pathway end product. These varied profiles result, in part, from inefficiency in the pathway which leads to increased accumulation of certain pathway intermediates in addition to the end product of the pathway. These intermediates have different biological activities and provide different benefits to the host than the pathway end products. I conducted a series of experiments to investigate the potential mechanisms by which fungi accumulate different profiles of intermediates and end products. In $A$. fumigatus, efficiency in completing the pathway varied developmentally. Wild type conidiating cultures containing all cell types involved in conidiation (hyphae, vesicle of conidiophore, phialides of conidiophore, and conidia) accumulated more of the pathway intermediate festuclavine and less of the pathway end product fumigaclavine $\mathrm{C}$ than did isolated mature conidia. Such differences also were indicated by studies with a medA mutant, which proliferates phialides. The medA mutant accumulated more pathway intermediates than did the wild type or a complemented medA mutant. A stuA mutant, lacking recognizable conidiophores, produced no detectable ergot alkaloids. Although this variation in alkaloid accumulation indicated a difference in distribution or activity of ergot pathway enzymes, fluorescence associated with the expression of five tested alkaloid pathway genes indicated a similar pattern of expression of each gene in the different cell types. Fluorescence was not observed in young hyphae but was detected at the apices of hyphae as they swelled to form the vesicle of the conidiophore. More fluorescence was observed in mature vesicles, phialides, and conidia. No qualitative differences were observed in cell type-specific expression of different pathway genes, indicating that observed differences in accumulation of intermediates versus end product must be due to quantitative differences in expression or differences in activity of pathway enzymes. In Neotyphodium lolii $\times$ Epichloë typhina isolate Lp1, an endophytic symbiont of perennial ryegrass, different ergot alkaloid profiles were observed in different tissues of the host plant. RNA interference (RNAi) and overexpression of the easA gene genetically manipulated the flux of metabolites down the pathway. When compared to wild type, knock-down of eas $A$ gene resulted in higher accumulation of a pathway intermediate and a shunt product in comparison to pathway end product. In contrast, over-expression of eas $A$ resulted in higher accumulation of the pathway end product and no significant difference in the accumulation of intermediates and shunt products of the pathway. Collectively, my results indicated that the efficiency of the ergot pathway varies at cellular level in A. fumigatus and at the tissue level in Neotyphodium sp. Lp1. Also, in Neotyphodium sp. Lp1, efficiency in the flow of intermediates down the ergot alkaloid pathway can be manipulated by altering the expression of easA. 


\section{DEDICATION}

I would like to dedicate this research to my advisor, Dr. Dan Panaccione. Without his guidance, teaching, insightful ideas this dissertation could not have been completed. I cannot adequately express my thanks for his help and interest in seeing me obtain not only my degree, but succeed in all my endeavors. I will always be thankful for the flexibility and freedom that he has provided me in doing my research. For all his help and mentoring, I am very grateful. 


\section{ACKNOWLEDGEMENTS}

First and foremost I would like to express my deepest gratitude to my advisor, Dr. Dan Panaccione for providing me the wonderful opportunity to work in his lab.I have been very fortunate to have an advisor who gave me the freedom to explore on my own and at the same time provide me guidance when needed. I am also very indebted to my committee members, Dr. Christopher L. Schardl, Dr. Jianbo Yao, Dr. Joseph B. Morton, and Dr. Jed H. Doelling for sharing their passion for research and for their constant guidance and support. I would also like to thank Dr. Dale Karlson for his support during my first two years of PhD, and Dr. Barton Baker for providing assistance during my time at WVU. I would also like to thank Natalie Allen, Chris Moore, Katy Ryan, JR Liggett and Sarah Robinson for all their assistance in the lab.

I would like to thank all my colleagues and friends within Environmental Microbiology and Plant Pathology. I have never met a more dynamic group of people than this, they were always there to help and support in anyway possible. I would especially like to mention Kelly Mayhew, Bill Wheeler, Natalie Allen, Katy Ryan, Chris Moore, JR Liggett, Sonia Purin, Rob Bills, Tiara King, Mariana Farcas, Christine Coyle, Dr. Gary Bissonnette. Many friends have helped me stay sane through these years. Their support and care helped me overcome setbacks and stay focused on my graduate study. I greatly value their friendship and I deeply appreciate their belief in me.

I want to thank my best friend Swamy, for always being there to help me and my family. It is very hard to find such a great friend who also shares the same passion for research. Good luck Swamy, I'm sure you'll be successful where ever you go.

I would like to express my heart-felt gratitude to my family. My parents who have always been so supportive, for teaching me that even the largest task can be accomplished if it is done one step at a time. I want to specially thank my mom who always helped me out with the kids, I could not have done it without her help. I want to thank my brother and sister-in-law for all their support. My biggest strength are my four angels, my kids Tanusha and Jay, my niece and nephew Aarav and Anisha. Everytime I see their sweet smiles it gives me so much strength. I am very blessed to have them in my life. I want to specially thank my darling daughter Tanusha for being supportive and saying to me every single day that I am the best mother on the whole planet.

And lastly, I want to thank the most important person without whom I could not have done anything, my husband Damodar. I give my deepest expression of love and appreciation for the encouragement that he has given me and sacrifices he made during the last couple of years. Thank you for keeping me sane, helping me keep perspective on what is important in life and for showing me how to deal with reality.

I want to specially remember my grandfather who has taught me to be kind to everybody and assist both friends and strangers in need. He always taught me to chase my dreams. I miss you grandpa. 


\section{TABLE OF CONTENTS}

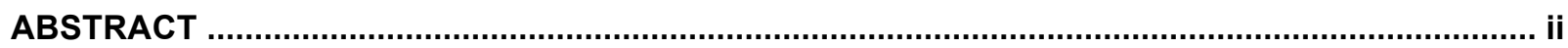

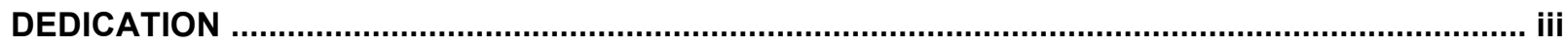

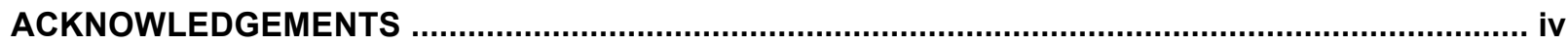

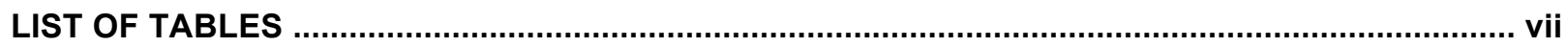

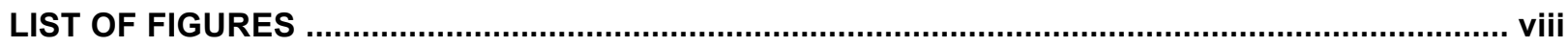

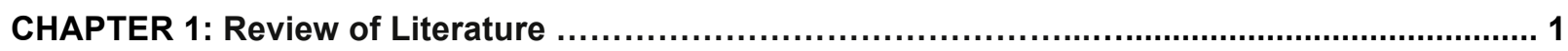

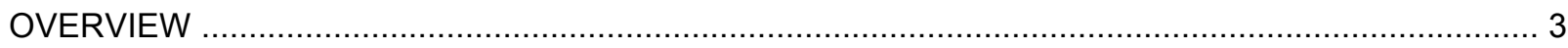

ERGOT ALKALOID AND THEIR HISTORICAL SIGNIFICANCE................................................ 3

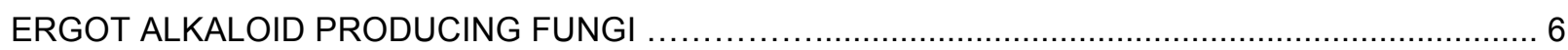

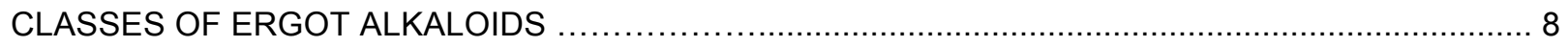

DIVERSITY IN THE PRODUCTION OF ERGOT ALKALOID AMONG PRODUCING FUNGI ...............11

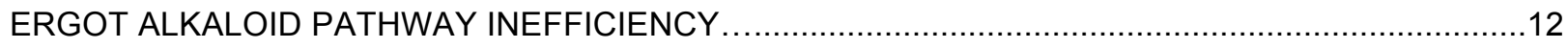

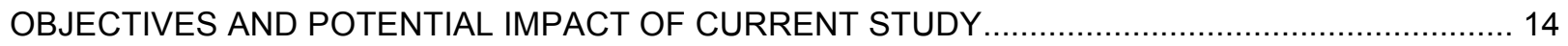

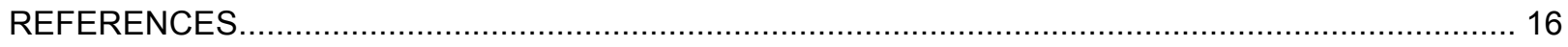

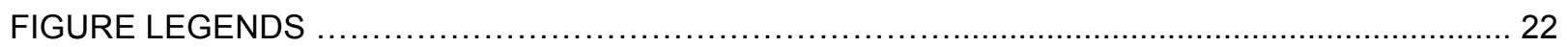

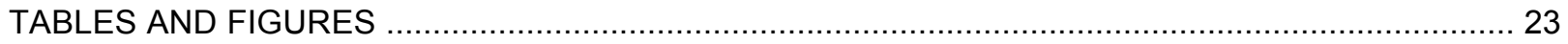

CHAPTER 2: Spatial expression patterns of ergot alkaloid genes during conidiophore

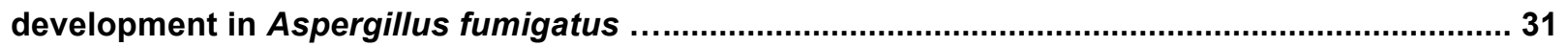

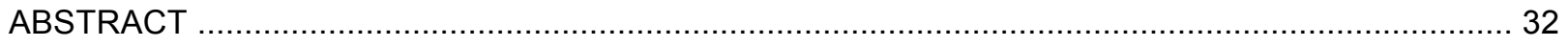

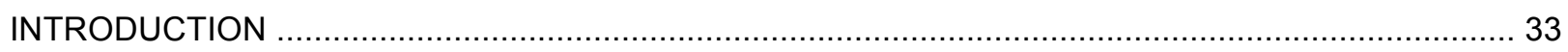

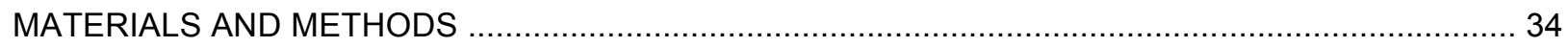

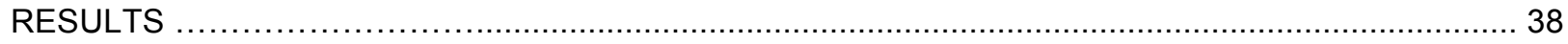

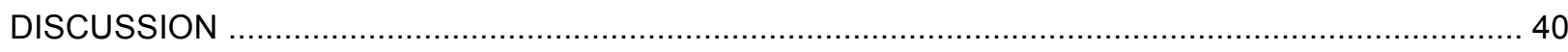

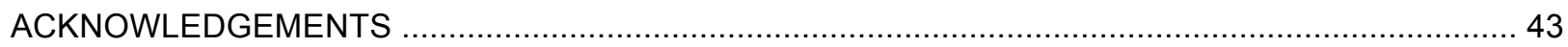




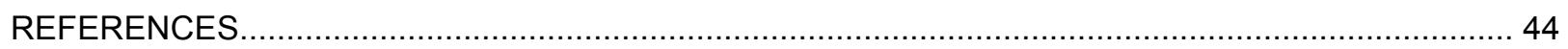

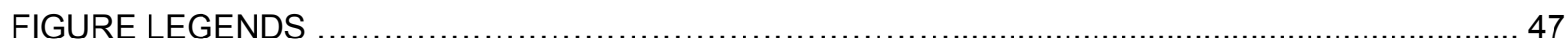

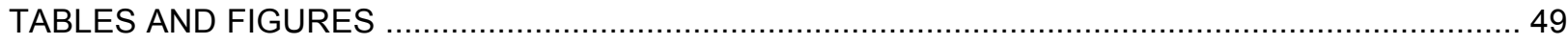

CHAPTER 3: Investigation and genetic modification of ergot alkaloid efficiency of Neotyphodium Iolii × Epichloë typhina isolate Lp1 (Neotyphodium sp. Lp1) ......................................... 55

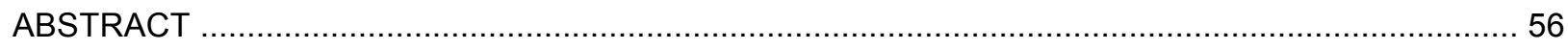

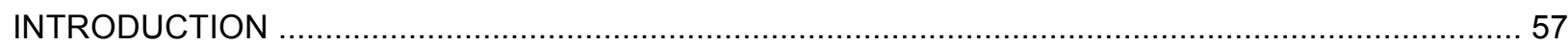

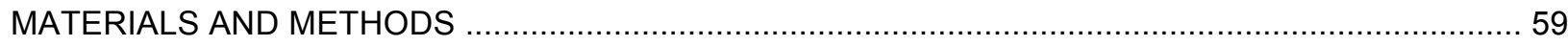

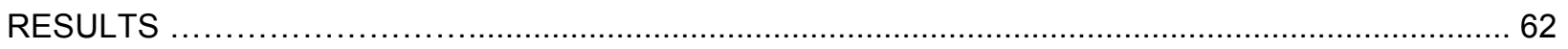

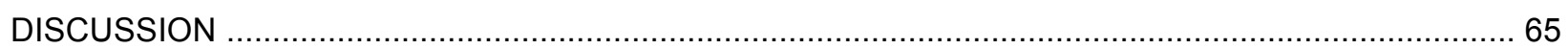

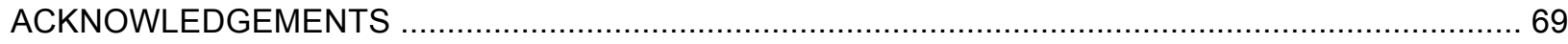

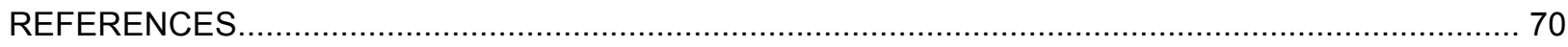

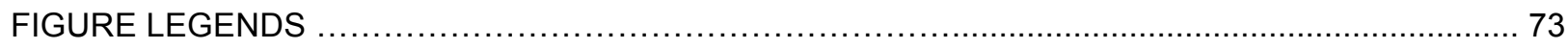

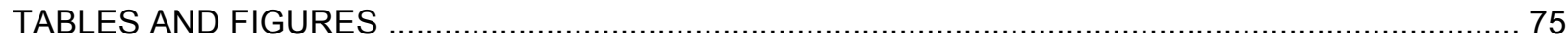

APPENDIX 1: Real-time PCR analysis of grass symbiota containing wild-type and mutant Neotyphodium Iolii × Epichloë typhina isolate Lp1 (Neotyphodium sp. Lp1) .............................. 85

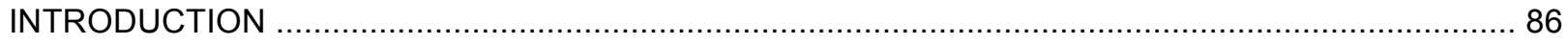

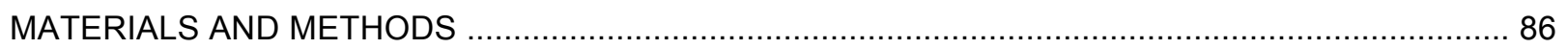

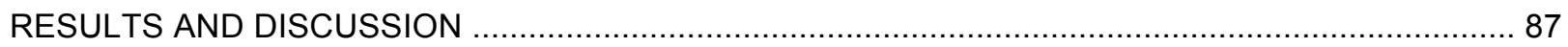

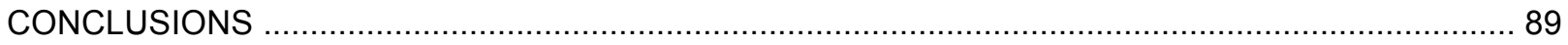

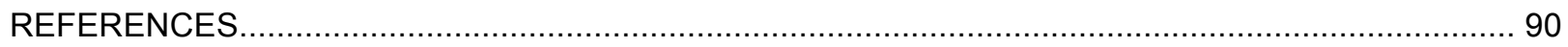

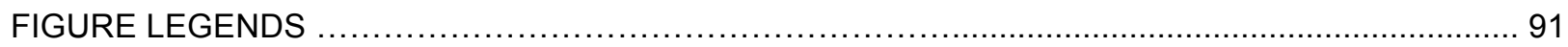

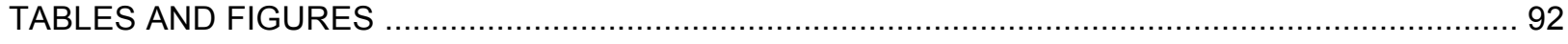

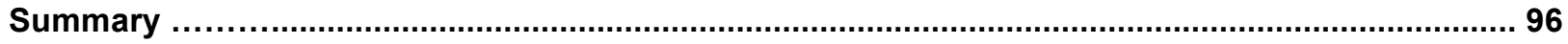

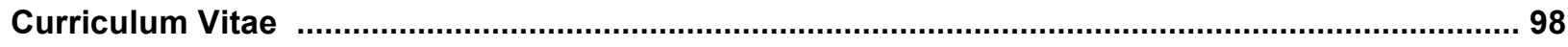




\section{LIST OF TABLES}

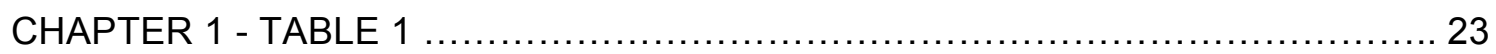

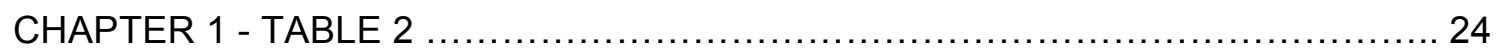

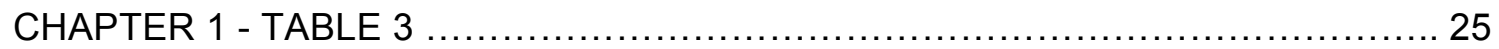

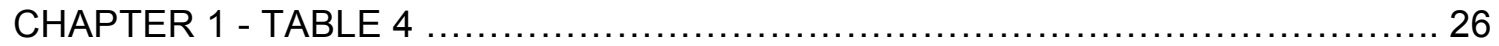

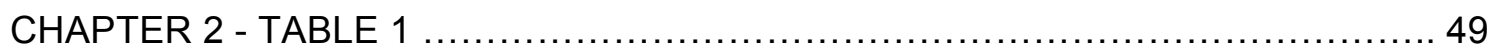

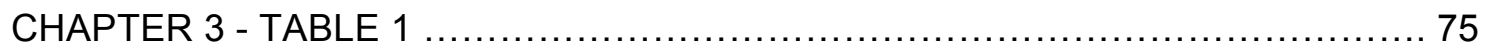

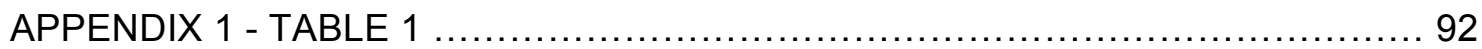




\section{LIST OF FIGURES}

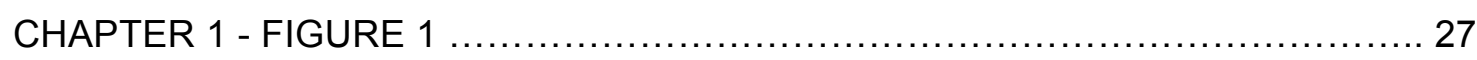

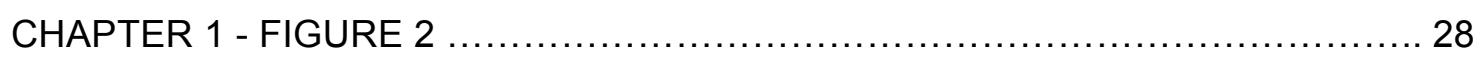

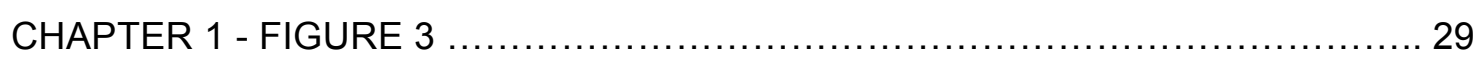

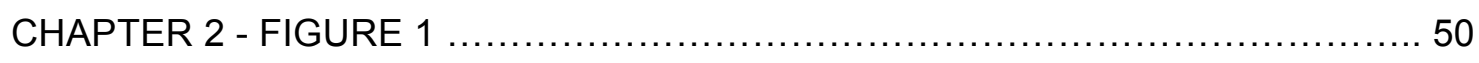

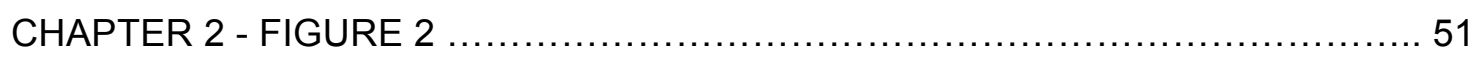

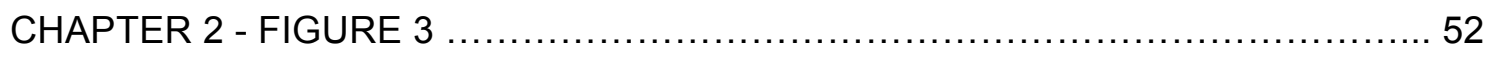

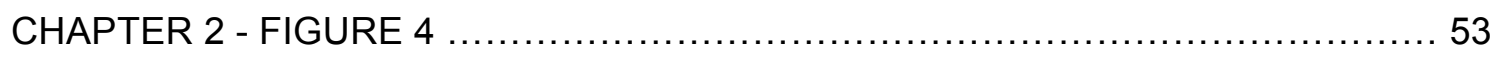

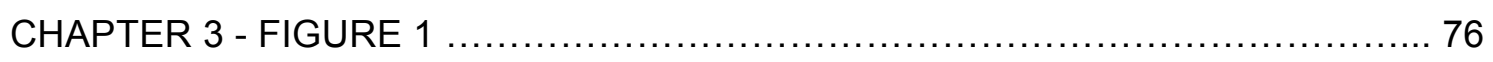

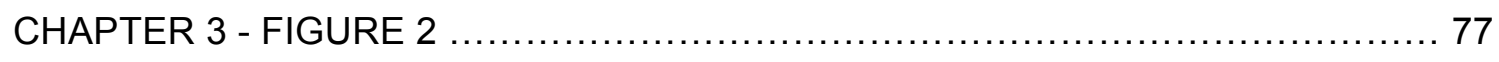

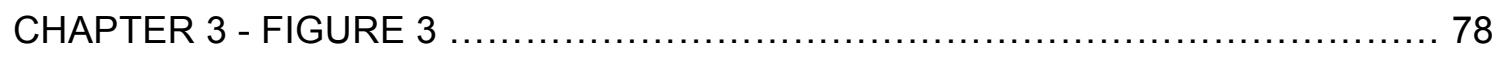

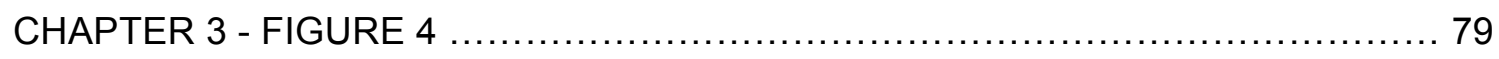

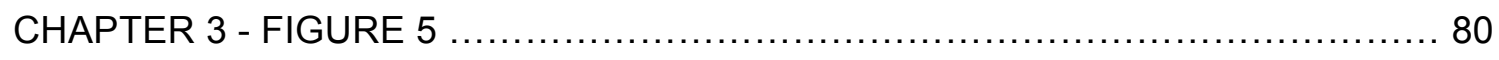

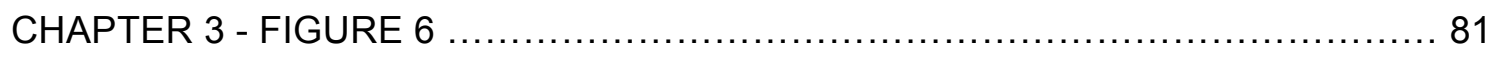

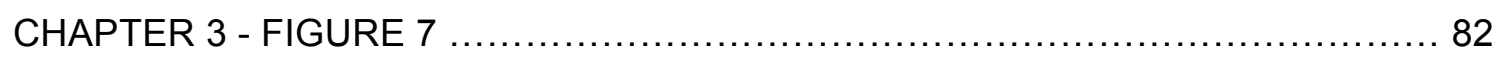

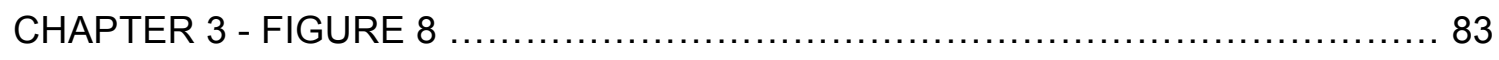

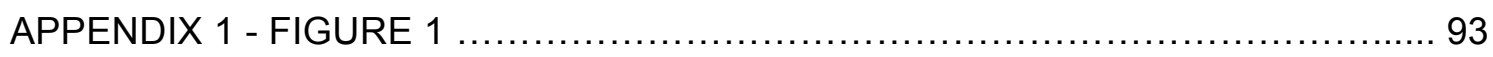

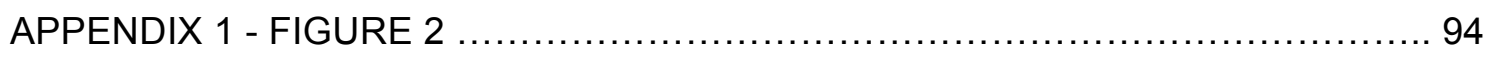

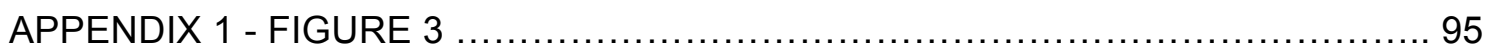


CHAPTER-1 


\section{REVIEW OF LITERATURE}




\section{Overview}

Ergot alkaloids were first discovered in the sclerotia of the ergot fungus, Claviceps purpurea. They are mycotoxins that exert toxic effects on humans and animals. While ergot alkaloids are better known for their toxicity, they also have pharmaceutical properties (Pertz and Eich, 1999; Tudzynski et al., 2001; Panaccione and Schardl, 2003). Ergot alkaloids have been extensively studied in C. purpurea, and are also reported in other species, such as certain Penicillium spp., Aspergillus fumigatus, and several epichloae (Epichloë and Neotyphodium spp.) that are endophytes of grasses (Panaccione and Schardl, 2003; Schardl et al., 2006). There is a very high degree of variation in the types of ergot alkaloids produced within an individual and among producers from different taxa, which means different fungi accumulate different profiles of ergot alkaloids rather than a single pathway end product. Some of the variation in ergot alkaloid profiles results from inefficiency in the pathway which leads to accumulation of the pathway intermediates (Panaccione, 2005). The pathway is particularly inefficient in grass endophytes, which leads to high levels of intermediate and by-product accumulation relative to the end product of the pathway. This pathway inefficiency may be beneficial to the fungus because different ergot alkaloids have different biological activities and thus, could play a major role in the survival of the fungus.

\section{Ergot alkaloids and their historical significance}

Ergot alkaloids are a complex family of indole-derived mycotoxins with diverse biological activities. They affect humans and livestock, and the extent of damage depends on 
various factors such as strength of the toxins, time of exposure, and the individual's health. These alkaloids typically affect the central nervous, immune, circulatory and reproductive systems (Grocer and Floss, 1998; Pertz and Eich, 1999; Tudzynski et al., 2001; Panaccione and Schardl, 2003). Historically, humans suffered from ergotism, also known as the "Devils curse" or "St. Anthony's fire," upon consumption of grain contaminated with sclerotia of the ergot fungus, Claviceps purpurea. The ergot alkaloids retain their activity even after the contaminated grain has been made into bread (Peraica et al., 1999). There are two distinct types of ergotism, gangrenous and convulsive ergotism, based on the type of alkaloid involved. Gangrenous ergotism results in gangrene of the limbs, and is usually caused by ergopeptine alkaloids, because of their vasoconstrictive properties. Convulsive ergotism, which is more typically caused by intoxication with ergot clavines or simple amides of lysergic acid, is characterized by hallucinations, involuntary muscle contractions and gastrointestinal problems. However, there is significant overlap in the types of symptoms induced by different ergot alkaloid sources. Ergotism is now a rare occurrence because of various precautions such as grain cleaning before milling which removes most of the alkaloids, and crop rotation. The last documented outbreak of ergotism due to ergot clavines was seen in India in 1975 (Peraica et al., 1999) and that due to ergotamine was reported in Ethiopia in 1977 (Demeke et al., 1979). However, ergot poisoning is still a major concern in domestic animals such as cattle, chicken, sheep, horses and pigs that usually feed on contaminated grasses or grains (Bennett and Klich, 2003; Fribourg and Waller 2005). It has been reported that cattle grazing on endophyte infected tall fescue have lowered average daily weight gains, higher body temperatures, rougher coats, 
lowered prolactin production, and reduced conception rates (Fribourg and Waller, 2005). Ergot alkaloids have also been shown to affect rabbits, insects, and bacteria (Eich and Pertz, 1999; Clay and Schardl, 2002; Panaccione and Schardl, 2003; Popay and Bonos, 2005; Panaccione et al., 2006; Potter et al., 2008).

Ergot alkaloids have high biological activity and a broad spectrum of pharmacological effects, hence they are of considerable importance to medicine. In general, the pharmacological effects of all the ergot alkaloids appear to result from their actions as partial agonists or antagonists at different adrenaline, dopamine, and serotonin receptors, which further affect nervous, circulatory, reproductive, and immune systems (Goetz and Diederich, 1992; Pertz and Eich, 1999; Ganetsky and Brush, 2005). Their roles as agonists or antagonists vary depending on which receptors they bind (Stadler and Groger,1984). Ergot alkaloids in controlled doses can have a therapeutic effect, and have been used in medicine as anti-migraine agents (ergotamine), in treatment of Parkinson's disease (bromocriptine), in treating postpartum hemorrhages and mastopathy, and to induce uterine contractions in childbirth (ergonovine) (Kimball et al., 1989; Goetz and Diederich, 1992; Wadworth and Chrisp, 1992; van Dongen and de Groot, 1995; Barceloux, 2008). They also have a sedative effect on the central nervous system. However, because of their lack of specificity for individual monoamine receptors, they have a propensity for undesirable side effects (Kozlovsky, 1999; Panaccione and Schardl, 2003).

Ergot alkaloids may also be synthesized in vitro. During the 1940's, a Swiss chemist named Albert Hofmann created the semi-synthetic ergot alkaloid lysergic acid diethylamide (LSD), which became a well known recreational drug (Hofmann, 1980). He 
discovered the hallucinogenic properties of the drug after accidentally ingesting it. LSD was used by psychiatrists and the Central Intelligence Agency (CIA) (Bennett and Klich, 2003). Use of LSD has been known to cause a condition known as serotonin syndrome, which is a condition that shares similar clinical features with convulsive ergotism (Eadie, 2003; Ganetsky and Brush, 2005).

\section{Ergot alkaloid producing fungi}

The distribution of fungi producing ergot alkaloids appears to be non-coherent paraphyletic. Several fungi representing the two distantly related orders within the phylum Ascomycota, Eurotiales and Hypocreales, produce ergot alkaloids (Panaccione, 2005). Within the Hypocreales, ergot alkaloids have been most extensively studied in the clavicipitaceous genus Claviceps and several fungi in the genera Epichloe and Neotyphodium, which live as endophytic symbionts in grasses (Panaccione and Schardl, 2003; Schardl et al., 2006). Claviceps spp. parasitize flowers of rye and related cereal and forage plants and produce fungal overwintering bodies, the ergot sclerotia that replace the host's seeds. Consumption of grain or seeds contaminated with the sclerotia can cause ergotism in humans and other mammals. Neotyphodium spp. and their teleomorphs, Epichloë spp., are endophytes of cool-season grasses, such as tall fescue and perennial ryegrass (Schardl et al., 2006). Endophytic association of the plants can be either mutualistic or antagonistic (Clay and Schardl, 2002). Mutualistic association can be seen in the case of Neotyphodium spp. which live in the host plant asymptomatically, actively growing in the intercellular spaces and colonizing the plants more extensively at the base of the pseudostem. During flowering, the endophyte 
colonizes the floral meristem wherein hyphae extensively colonize the seeds beneath the seed coat. Thus the next generation seedlings become pre-inoculated with the endophyte. The asexual fungi are transmitted only vertically via the infected seeds (Craven et al., 2001; Clay and Schardl, 2002; Malinowski and Belesky, 2006). These fungi have significant effects on their host plants such as increased tolerance to various biotic and abiotic factors, including increased resistance to herbivores. Endophyte infection has also been associated with increases in tiller number, seed production, and root growth (Bush et al., 1997; Schardl and Phillips, 1997; Clay and Schardl, 2002; Panaccione, 2005; Malinowski and Belesky, 2006).

In pathogenic associations, the endophyte grows asymptomatically inside the host plant until the plant reaches the boot stage, after which the fungus reproduces sexually by producing a fungal sexual structure, called a stroma that inhibits the development of the grass inflorescence (Clay and Schardl, 2002). The most pathogenic of these fungi are transmitted only horizontally. Some of the endophytic fungi such as $E$. festucae can be transmitted both vertically and horizontally; they affect only some inflorescences by forming stromata, whereas other inflorescences on the same plant produce infected seeds (Schardl and Leuchtmann, 2005; Olejniczak and Lembicz, 2007).

Endophytes have also been associated with livestock toxicosis, which is attributed, at least in part, to the ergot alkaloids that they produce (Hill et al., 1994; Filipov et al., 1998; Gadberry et al., 2003). In the U.S.A., cattle and horses that grazed on tall fescue inhabited by the endophyte $N$. coenophialum suffer from fescue toxicosis, symptoms of which include low fertility, poor weight gain, poor milk production, low 
immunity, and dry gangrene of the limbs and tail (Lyons et al., 1986; Porter and Thompson, 1992; Schardl and Phillips, 1997; Gadberry et al., 2003). Livestock toxicosis can also be caused by several Claviceps species, endophytic fungi such as Epichloë (anamorph Neotyphodium) spp. that complete their life cycles in association with coolseason grasses symbionts (Schardl, 1996; Schardl et al., 2009).

Several species of fungi belonging to the order Eurotiales, such as Aspergillus fumigatus (Spilsbury and Wilkinson, 1961) and Penicillium commune (Kozlovsky, 1999), which are common imperfect fungi, also produce ergot alkaloids. A. fumigatus is an opportunistic pathogen capable of growing at temperatures up to $55^{\circ} \mathrm{C}$ and surviving at $70^{\circ} \mathrm{C}$. It colonizes domestic and public buildings causing aspergillosis, especially in immune-deficient individuals. The fungus grows in moist areas, such as basements and ventilation system ducts; it also is ubiquitous outdoors, with higher concentrations in areas surrounding compost and waste removal facilities. The fungus reproduces asexually by producing conidia, which become airborne and can be inhaled by humans and animals. In some cases inhaled conidia can infect and cause disease, act as an allergen, cause toxicoses, or cause inflammatory responses (Fischer and Dott, 2003).

\section{Classes of ergot alkaloids}

Ergot alkaloids are group of natural biologically active compounds that range from simple tricyclic to more complex tetracyclic alkaloids. Ergot alkaloids are considered secondary metabolites because under ideal laboratory conditions, they are not essential for survival of the fungus, yet they have an effect on other organisms that are exposed to the fungus producing these alkaloids. The type of alkaloid produced depends on the 
pathway enzymes present in the producing fungus and the efficiency of the particular pathway (Panaccione, 2005; Schardl et al., 2006). Ergot alkaloids are tryptophan derivatives that contain a basic tetracyclic ergoline ring structure, which is methylated at position N-6 (Fig. 1). Based on the substitutions present at the C-8 position of the ergoline ring, they may be broadly divided into three groups: clavines, ergopeptines, and simple amides of lysergic acid (Fig 1) (Flieger et al., 1997; Keller, 1999). Some clavines, which are usually considered as the simpler ergot alkaloids, are precursors of lysergic acid; whereas both simple amides and ergopeptines, non-ribosomally synthesized peptides, derivatives formed from lysergic acid and three hydrophobic Laminoacids (Panaccione et al., 2006b; Schardl et al., 2006).

Clavines have been isolated from many Claviceps spp. and other non-ergot fungi. Clavines can be further differentiated based on the presence of double bond between carbon 8 and 9 or 9 and 10, or by presence of open form of ring $D$ of the tetracyclic ergoline ring which can be found in chanoclavine and members within the subclass 6,7-secoergolines (Flieger et al., 1997). In some fungi such as $A$. fumigatus and Claviceps fusiformis, clavines are the ultimate end products of the ergot alkaloid pathway; however, in other ergot alkaloid-producing fungi they are intermediates to more complex ergot alkaloids or as products of shunts off the pathway. Based on feeding experiments using endophyte infected grasses in rabbits it was discovered that apart from causing toxicoses, clavines also affect food preference by reducing the appeal of the infected grasses (Panaccione et al., 2006a).

Simple amides of lysergic acid include lysergic acid amide (ergine) (Fig. 1), ergonovine, lysergic acid-2-hydroxyethylamide, and lysergyl alanine (Panaccione and 
Schardl, 2003; Panaccione et al., 2003). They are produced by various fungi such as $C$. paspali (accumulates ergine and lysergic acid-2-hydroxyethylamide), C. purpurea (accumulates ergonovine and lysergyl-alanine), Neotyphodium sp. Lp1 and N. coenophialum (accumulate ergine and lysergyl-alanine). Based on knock-out analysis in Neotyphodium sp. Lp1, it has been determined that these alkaloids can accumulate as by-products of ergopeptine synthesis as seen in the case of ergine and lysergyl alanine (Panaccione and Schardl, 2003) or they can accumulate as ultimate end products of the ergot pathway as in ergonovine in C. purpurea (Ortel and Keller, 2009).

Ergopeptines, also known as cyclol ergot alkaloids are the most complex ergot alkaloids. They were also the first to be isolated and studied. They are nonribosomallysynthesized peptides that have three L-amino acids attached to D-lysergic acid via peptide bond, which is catalyzed by a lysergyl peptide synthetase complex (Riederer et al., 1996). The LPS complex is made up of two separate polypetides, LPS2 that activates D-lysergic acid by adenylation, and LPS1, which recognizes and activates the amino acids and forms the ergopeptines. Based on the amino acids that occupy positions I and II of the tripeptide chain attached to lysergic acid, there is variation in the composition of the ergopeptines (Fig. 2). Usually position III of the tripeptide chain is occupied by amino acid proline, with the only exception being ergobalansine, where position III is occupied by alanine (Keller, 1999). Based on the amino acid in position I of the peptide, ergopeptines can be divided into three subclasses: the ergotamine group, ergotoxine group, and ergoxine group. Based on the amino acid residing in position II there is lot of variation in individual ergot alkaloids within subclasses (Table 1). Possible amino acids occupying this position are phenylalanine, leucine, isoleucine, valine, and 
alpha-amino butyric acid (Schardl et al., 2006). Ergovaline is a major alkaloid found within Neotyphodium spp., whereas ergosine and ergotamine are examples of abundant ergopeptines within Claviceps spp. (Lyons et al., 1986; Panaccione, 2005).

Ergopeptams, are also known as noncyclol lactam ergot alkaloids, due to the lack of hydroxylation reaction at the amino acid adjacent to lysergic acid (position I); hence a cyclol bridge is unable to form with the amino acid in position III. They differ from ergopeptines in having a D- proline and a noncyclol lactam tripeptide chain (Flieger et al., 1997; Keller, 1999). Ergopeptams are further classified into the subclasses, ergotamams, ergoxams, ergotoxams, and ergoannams based on aminoacid in positions I and II (Table 2).

\section{Diversity in the production of ergot alkaloids among producing fungi}

Based on ergot alkaloid profiles and gene cluster analysis it has been elucidated that ergot alkaloid producing fungi belonging to Hypocreales and Eurotiales, two distant ascomycete orders, share early steps of the ergot alkaloid pathway; alternate pathways diverge after these common early steps resulting in the production of different sets of ergot alkaloids in different ergot alkaloid producing fungi. Aspergillus fumigatus, belonging to order Eurotiales, accumulates several simple clavine alkaloids with a saturated $D$ ring like festuclavine, fumigaclavine $A$, and fumigaclavine $B$ in the process of producing the ultimate pathway end product fumigaclavine $\mathrm{C}$. It does not produce any complex lysergyl alkaloids (Coyle and Panaccione, 2005). Whereas several Claviceps, Epichloe and Neotyphodium species (family Clavicipitaceae) usually accumulate a more complex combination of clavines, ergopeptines, and simple amides of lysergic acid 
(Panaccione et al., 2006b). Neotyphodium sp. Lp1, an endophyte of perennial ryegrass, accumulates relatively high concentrations of clavines and the ergopeptine ergovaline (Panaccione et al., 2003; Panaccione et al., 2006b), but this accumulation may vary in different host tissues (Table 3). Different species of Claviceps accumulate different alkaloids in their overwintering structures, sclerotia ("ergots"). Claviceps fusiformis accumulates clavines up through elymoclavine, and it completely lacks ergopeptines and simple amides (Lorenz et al., 2007). C. purpurea accumulates mostly simple amides of lysergic acid and ergopeptines (Tudzynski et al., 2001), whereas C. africana, an ergot fungus of sorghum has high levels of clavines and dihydroergot type of ergopeptines (Panaccione and Schardl, 2003).

\section{Ergot alkaloid pathway inefficiency}

In addition to the above indicated diversity in the ergot alkaloid profiles among different fungi, ergot alkaloid structure and function also differ within an individual ergot alkaloid producer. The ergot alkaloid pathway is relatively long (Fig.3) and product of the pathway is not one single toxin but a mixture of end product, one or more intermediates which accumulate to high concentrations, and alternate products that are produced by short shunt pathways off of the main pathway (Panaccione, 2005). These shunt pathways may influence pathway flux or accumulation of intermediates through the main pathway, while also accounting for the production of additional products which contribute to the diversity of ergot alkaloid profile (Panaccione, 2005). Some of the most important shunt pathways include the ones that lead to the production of $6,7-$ secolysergine in some Neotyphodium spp. endophytes (Panaccione et al., 2003) and 
setoclavine in some of the endophytic fungi belonging to Clavicipitaceae (Panaccione and Schardl, 2003; Schardl et al., 2006). So, the ergot alkaloid pathway is considered inefficient because there is limited direct flow of intermediates into one final end product; instead there may be very high levels of intermediates accumulating at certain points in the pathway, and also, in certain producers, these intermediates are diverted into alternate products. In the perennial ryegrass endophyte Neotyphodium Iolii x Epichloë typhina isolate Lp1, the pathway is considered to be highly inefficient because of high accumulation of intermediate (chanoclavine) and spur products (6,7-secolysergine and setoclavine) relative to the pathway end product (ergovaline) (Panaccione et al., 2003; Panaccione et al., 2006b). This flow of intermediates may also vary in different tissues (Table 3). This pathway is also evident in A. fumigatus were there is difference in the ergot alkaloid profile of mature conidia compared to the whole conidiating cultures (Table 4). Based on studies with model animals and knockout endophytes, it has been demonstrated that the pathway inefficiency, which results in accumulation of intermediates and alternate products in addition to the end product, provides an advantage to the producing fungus and its plant host (Panaccione et al., 2006a; Potter et al., 2008). These studies have shown that intermediates and end products have different biological activities, intermediates act as feeding deterrents and the pathway end products have effective anti-insect activity (Panaccione et al., 2006a; Potter et al., 2008). The pathway inefficiency that is accounted for in these fungi could be a result of variation in the expression of different ergot alkaloid pathway genes. Different cell types (in case of A. fumigatus) or hyphal compartments in different contexts (in case of endophytes) could possibly express different subsets of ergot alkaloid pathway genes or 
all cell types could express all pathway genes but their expression is modulated in such a way that it leads to accumulation of different ergot alkaloids. These questions can be answered based on results from the GFP-based assays in A. fumigatus and real-time PCR analysis in Neotyphodium sp. Lp1.

\section{Objectives and potential impact of current study}

The focus of this study is to understand the biochemistry of ergot alkaloid pathway inefficiency in two different fungal species which differ markedly in development and life history. Aspergillus fumigatus, a saprophytic and opportunistic human pathogen provides us with the advantage of studying the pathway inefficiency in the different cell types of the fungus. The other fungal species Neotyphodium lolii x Epichloë typhina isolate Lp1, an obligate symbiont of perennial ryegrass enables us to study and manipulate the pathway inefficiency in different tissues of the host plant. The objectives of this study were to:

1. Investigate potential spatial basis for ergot alkaloid pathway inefficiency in $A$. fumigatus by application of GFP-based assays.

2. Experimentally quantify the tissue specific variation of ergot alkaloid accumulation due to pathway inefficiency in endophyte infected grasses.

3. Manipulate the ergot pathway inefficiency by genetically modifying the ergot alkaloid gene expression in perennial ryegrass endophyte Neotyphodium sp. Lp1 through overexpression and RNAi approaches.

Endophyte associated livestock toxicoses cause significant problems in agriculture that might be ameliorated by using genetically modified endophytes 
produced by strategies developed in this research. Analysis of the pathway inefficiency will aid in identifying the possible basis by which ergot alkaloid profiles are altered in different fungi, this information can be further utilized in regulating the ergot pathway for more beneficial purposes. Characterization of the ergot alkaloid pathway inefficiency and the ability to control the spectrum of alkaloids produced may lead to advances in these fields by providing a potential means of eliminating the undesired effects. Knockdown and overexpression study analysis from this research can be extended to other endophytic fungi were gene knockout studies are difficult to perform. 


\section{REFERENCES}

Barceloux, D. G. (Ed.) 2008. Medical Toxicology of Natural Substances: foods, fungi, medicinal herbs plants and venomous animals. John Wiley \& Sons, Inc.

Bennett, J.W., Klich, M. 2003. Mycotoxins. Clin Microbiol Rev 16, 497-516.

Bush, L.P., Wilkinson, H.H., Schardl, C.L. 1997. Bioprotective alkaloids of grass-fungal endophyte symbioses. Plant Physiol 114, 1-7.

Clay, K., Schardl, C. 2002. Evolutionary origins and ecological consequences of endophyte symbiosis with grasses. Am Nat 160 Suppl 4, S99-S127.

Coyle, C.M., Panaccione, D.G. 2005. An ergot alkaloid biosynthesis gene and clustered hypothetical genes from Aspergillus fumigatus. Appl Environ Microbiol 71, 3112-3118.

Craven, K. D., Blankenship, J. D., Leuchtmann, A., Hignight, K., Schardl, C. L. 2001. Hybrid fungal endophytes symbiotic with the grass Lolium pratense. Sydowia 53, 44-73. Demeke, T., Kidane, Y., Wuhib, E. 1979. Ergotism--a report on an epidemic, 1977-78. Ethiop Med J 17, 107-113.

Eadie, M.J. 2003. Convulsive ergotism: epidemics of the serotonin syndrome? Lancet Neurol 2, 429-434.

Eich, E., H. Pertz. 1999. Antimicrobial and antitumor effects of ergot alkaloids and their derivatives, p. 411-440. In V. Kren and L. Cvak (ed.), Ergot: The Genus Claviceps. Harwood Academic Publishers, The Netherlands.

Filipov, N.M., Thompson, F.N., Hill, N.S., Dawe, D.L., Stuedemann, J.A., Price, J.C., Smith, C.K. 1998. Vaccination against ergot alkaloids and the effect of endophyteinfected fescue seed-based diets on rabbits. J Anim Sci 76, 2456-2463. 
Fischer, G., Dott, W. 2003. Relevance of airborne fungi and their secondary metabolites for environmental, occupational and indoor hygiene. Arch Microbiol 179, 75-82.

Flieger, M., Wurst, M., Shelby, R. 1997. Ergot alkaloids--sources, structures and analytical methods. Folia Microbiol (Praha) 42, 3-29.

Fribourg, H. A., Waller, J.C. 2005. Neotyphodium research and application in the USA, p. 3-22. In C. A. Roberts, C. P. West, and D. E. Spiers (ed.), Neotyphodium in coolseason grasses, 1st ed. Blackwell Publishing Professional, Ames, lowa.

Gadberry, M.S., Denard, T.M., Spiers, D.E., Piper, E.L. 2003. Effects of feeding ergovaline on lamb performance in a heat stress environment. J Anim Sci 81, 15381545.

Ganetsky, M., Brush, D.E. 2005. Serotonin Syndrome- What Have We Learned? Pediatric Emergency Medicine 6, 103-108.

Goetz, C.G., Diederich, N.J. 1992. Dopaminergic agonists in the treatment of Parkinson's disease. Neurol Clin 10, 527-540.

Groger, D., Floss, H. 1998. Biochemistry of ergot alkaloids--achievements and challenges. In The Alkaloids: Chemistry and Biology 50, 171-218.

Hill, N.S., Thompson, F.N., Dawe, D.L., Stuedemann, J.A. 1994. Antibody binding of circulating ergot alkaloids in cattle grazing tall fescue. Am J Vet Res 55, 419-424. Hofmann, A. 1980. LSD, my problem child!' 209.

Keller, U. 1999. Biosynthesis of ergot alkaloids, p. 95-163. In V. Kren and L. Cvak (ed.), Ergot: The Genus Claviceps. Harwood Academic Publishers, The Netherlands. Kimball, B.P., LiPreti, V., Aldridge, H.E. 1989. Quantitative arteriographic responses to ergonovine provocation in subjects with atypical chest pain. Am J Cardiol 64, 778-782. 
Kozlovsky, A. G. 1999. Producers of ergot alkaloids out of Claviceps genus, p. 479499. In V. Kren and L. Cvak (ed.), In Ergot: The Genus Claviceps. Harwood Academic Publishers, The Netherlands.

Lorenz, N., Wilson, E.V., Machado, C., Schardl, C.L., Tudzynski, P. 2007. Comparison of ergot alkaloid biosynthesis gene clusters in Claviceps species indicates loss of late pathway steps in evolution of C. fusiformis. Appl Environ Microbiol 73, 7185-7191. Lyons, P.C., Plattner, R.D., Bacon, C.W. 1986. Occurrence of peptide and clavine ergot alkaloids in tall fescue grass. Science 232, 487-489.

Malinowski, D., Belesky, D. 2006. Ecological importance of Neotyphodium spp. grass endophytes in agroecosystems. Grassland Science 52, 1-14.

Olejniczak, P., Lembicz, M. 2007. Age-specific response of the grass Puccinellia distans to the presence of a fungal endophyte. Oecologia 152, 485-494.

Ortel, I., Keller, U. 2009. Combinatorial assembly of simple and complex D-lysergic acid alkaloid peptide classes in the ergot fungus Claviceps purpurea. Journal of Biological Chemistry 284, 6650.

Panaccione, D.G., 2005. Origins and significance of ergot alkaloid diversity in fungi. FEMS Microbiol Lett 251, 9-17.

Panaccione, D.G., Cipoletti, J.R., Sedlock, A.B., Blemings, K.P., Schardl, C.L., Machado, C., Seidel, G.E. 2006a. Effects of ergot alkaloids on food preference and satiety in rabbits, as assessed with gene-knockout endophytes in perennial ryegrass (Lolium perenne). J Agric Food Chem 54, 4582-4587.

Panaccione, D., Schardl, C. 2003. Molecular genetics of ergot alkaloid biosynthesis, p. 399-424. In J. F. W. Jr., C. W. Bacon, N. L. Hywel- Jones, and J. W. Spatafora (ed.), 
The Clavicipitalean Fungi: Evolutionary Biology, Chemistry, Biocontrol, and Cultural Impacts. Marcel-Dekker, New York.

Panaccione, D. G., C. Schardl, and C. M. Coyle. 2006b. Pathways to diverse ergot alkaloid profiles in fungi, p. 23-52 In J. T. Romeo (ed.), Recent Advances in Phytochemistry, vol. 40. Elsevier, Amsterdam, The Netherlands.

Panaccione, D.G., Tapper, B.A., Lane, G.A., Davies, E., Fraser, K. 2003. Biochemical outcome of blocking the ergot alkaloid pathway of a grass endophyte. J Agric Food Chem 51, 6429-6437.

Peraica, M., Radić, B., Lucić, A., Pavlović, M. 1999. Toxic effects of mycotoxins in humans. Bull World Health Organ 77, 754-766.

Pertz, H., and E. Eich. 1999. Ergot alkaloids and their derivatives as ligands for serotoninergic, dopaminergic, and adrenergic receptors, p. 411-440. In V. Kren and L. Cvak (ed.), Ergot: The Genus Claviceps. Harwood Academic Publishers, The Netherlands.

Popay, A. J., and S. A. Bonos. 2005. Biotic responses in endophytic grasses, p. 163185. In C. P. W. C. A. Roberts, and D. E. Spiers (ed.), Neotyphodium in cool-season grasses, 1st ed. Blackwell Publishing Professional, Ames, lowa.

Porter, J.K., Thompson, F.N., 1992. Effects of fescue toxicosis on reproduction in livestock. J Anim Sci 70, 1594-1603.

Potter, D., Tyler Stokes, J., Redmond, C., Schardl, C., Panaccione, D. 2008.

Contribution of ergot alkaloids to suppression of a grass-feeding caterpillar assessed with gene knockout endophytes in perennial ryegrass. Entomologia Experimentalis et Applicata 126, 138-147. 
Riederer, B., Han, M., Keller, U. 1996. D-Lysergyl peptide synthetase from the ergot fungus Claviceps purpurea. Journal of Biological Chemistry 271, 27524.

Schardl, C.L., 1996. Epichloë Species: fungal symbionts of grasses. Annu Rev Phytopathol 34, 109-130.

Schardl, C. L. and Leuchtmann, A. 2005. The Epichloë endophytes of grasses and the symbiotic continuum,p. 475-503. In: J. Dighton, J. F. White, P. Oudemans, Eds.), The Fungal Community: its organization and role in the ecosystem. CRC Press, Boca Raton, Florida.pp.

Schardl, C.L., Panaccione, D.G., Tudzynski, P. 2006. Ergot alkaloids--biology and molecular biology. In The Alkaloids: Chemistry and Biology 63, 45-86.

Schardl, C., Phillips, T. 1997. Protective Grass Endophytes: Where are they from and where are they going? Plant Disease 81, 430-438.

Schardl, C. L., Scott, B., Florea, S. and Zhang, D.-X. 2009. Epichloë Endophytes: Clavicipitaceous Symbionts of Grasses,p. 275-305. In: H. Deising, (Ed.), The Mycota Plant Relationships, 2nd Edition. Springer-Verlag Berlin Heidelber.

Spilsbury, J. F., and S. Wilkinson. 1961. The isolation of festuclavine and two new clavine alkaloids from Aspergillus fumigatus Fres. J. Chem. Soc 5:2085-2091.

Stadler, P. A. and Giger, R.1984. Ergot alkaloids and their derivatives in medical chemistry and therapy,p. 463-485. In: L. P. Krosgard, C. H. Christensen, H. Kofod, Eds.), Natural products and drug development. Munksgaard, Copenhagen.

Tudzynski, P., Correia, T., Keller, U. 2001. Biotechnology and genetics of ergot alkaloids. Appl Microbiol Biotechnol 57, 593-605. 
Van Dongen, P.W., de Groot, A.N. 1995. History of ergot alkaloids from ergotism to ergometrine. Eur J Obstet Gynecol Reprod Biol 60, 109-116.

Wadworth, A.N., Chrisp, P. 1992. Co-dergocrine mesylate. A review of its

pharmacodynamic and pharmacokinetic properties and therapeutic use in age-related cognitive decline. Drugs Aging 2, 153-173. 


\section{FIGURE LEGENDS}

Figure 1: Representatives of the three classes of ergot alkaloids. Ergot alkaloids contain a basic ergoline ring structure indicated by the letters A-D within the alkaloid ergine. Based on substitutions on C-8 (blue) and location of the double bond (red), ergot alkaloids are divided into three groups: clavines which include festuclavine, simple amides of lysergic acid represented by ergine and ergotamine which represents ergopeptines.

Figure 2: Ergopeptines with varying amino acid substitutions. Ergopeptines are nonribosomally-synthesized peptides that have three L-amino acids attached to Dlysergic acid. They can be differentiated based on specific amino acids that occupy position R1 and R2. Usually, proline occupies the position R3. The table shows the amino acids involved in the synthesis of six common ergopeptines.

Figure 3: Overview of hypothesized ergot alkaloid pathways of $A$. fumigatus (indicated in red) and clavicipitaceous fungi (indicated in blue). DMAPP = dimethylallylpyrophosphate; $\mathrm{PPO}=$ pyrophosphate $; \operatorname{Trp}=$ tryptophan; DMAT = dimethylallyltryptophan. A. fumigatus and the clavicipitaceous fungi share early steps of the ergot alkaloid pathway up until chanoclavine after which $A$. fumigatus produces alkaloids indicated in red and clavicipitaceous fungi produce alkaloids indicated in blue. The pathways involved in 6,7-secolysergine and setoclavine synthesis are the shunt pathways that branch off the main pathway. 
Table 1. Representation of different subclasses of ergopeptine alkaloids

\begin{tabular}{|l|l|l|l|}
\hline & Ergotamines & Ergoxines & Ergotoxines \\
\hline \multicolumn{1}{|c|}{ Position I } & Alanine & $\alpha$-Amino butyric acid & Valine \\
\hline Position II & & & \\
\hline Leuchyalanine & Ergotamine & Ergostine & Ergocristine \\
\hline Isoleucine & $\alpha$-Ergosine & $\alpha$-Ergoptine & $\alpha$-Ergocryptine \\
\hline Valine & $\beta$-Ergosine & $\beta$-Ergoptine & $\beta$ - Ergocryptine \\
\hline$\alpha$-Amino butyric acid & Ergobine & Ergobutine & Ergopcornine \\
\hline
\end{tabular}


Table 2. Representation of different subclasses of ergopeptam alkaloids

\begin{tabular}{|l|l|l|l|l|}
\hline & Ergotamams & Ergoxams & Ergotoxams & Ergoannams \\
\hline Position II & Alanine & $\begin{array}{l}\alpha \text {-Amino } \\
\text { butyric acid }\end{array}$ & Valine & Isoleucine \\
\hline Phenyalanine & Ergotamam & Ergostam & Ergocristam & \\
\hline Leucine & $\alpha$-Ergosam & $\alpha$-Ergoptam & $\begin{array}{l}\alpha \text { - } \\
\text { Ergocrypta } \\
\mathrm{m}\end{array}$ & $\begin{array}{l}\alpha, \beta- \\
\text { Ergoannam }\end{array}$ \\
\hline Isoleucine & $\beta$-Ergosam & $\beta$-Ergoptam & $\begin{array}{l}\beta \text { - } \\
\text { Ergocrypta } \\
\mathrm{m}\end{array}$ & $\begin{array}{l}\beta, \beta- \\
\text { Ergoannam }\end{array}$ \\
\hline $\begin{array}{l}\text { Valine } \\
\text { E-Amino } \\
\text { butyric acid }\end{array}$ & Ergobam & Ergobutam & $\begin{array}{l}\text { Ergobutyra } \\
\mathrm{m}\end{array}$ & \\
\hline
\end{tabular}


Table 3. Percent of measured ergot alkaloids (molar basis) distributed among different intermediates and products in perennial ryegrass tissues infected with endophyte $L p 1^{1}$

\begin{tabular}{|l|c|c|c|}
\hline Ergot alkaloid & Leaf blades $^{2}$ & Pseudostems & Seeds \\
\hline Chanoclavine & 45 & 25 & 2 \\
\hline 6,7-secolysergine & 25 & 19 & 8 \\
\hline Setoclavine & 4 & 7 & 0 \\
\hline Lysergic acid & 0 & 0 & 12 \\
\hline Ergine & 6 & 5 & 26 \\
\hline Lysergyl-alanine & 1 & 0 & 5 \\
\hline Ergovaline & 18 & 45 & 48 \\
\hline
\end{tabular}

${ }^{1}$ Preliminary data collected by D.G.Panaccione from multiple perennial ryegrass plants, cv.Rosalin, infected with Neotyphodium sp.Lp1. However, samples were not necessarily from the same individuals grown under identical conditions.

${ }^{2}$ Values summed with columns vary from $100 \%$ due to rounding of multiple individual values. 
Table 4. Percent of measured ergot alkaloids (molar basis) distributed among different intermediates and products in cell types of cultured Aspergillus fumigatus ${ }^{1}$

\begin{tabular}{|l|c|c|}
\hline Ergot alkaloid & Abscised conidial only & Conidiating cultures $^{\mathbf{3}}$ \\
\hline Festuclavine & 8 & 65 \\
\hline Fumigaclavine B & 1 & 1 \\
\hline Fumigaclavine A & 4 & 6 \\
\hline Fumigaclavine C & 87 & 28 \\
\hline
\end{tabular}

${ }^{1}$ Unpublished data collected by C.M.Coyle and D.G.Panaccione

${ }^{2}$ Agar based cultures of A.fumigatus that are grown inverted will abscise ( or shed) mature conidia, which then accumulate on the lid of the culture plate, and can be harvested separately from the remainder of the culture.

${ }^{3}$ Composite of hyphae, condiophore vesicles, conidiophore phialides, and conidia. 


\section{FIGURE 1.}
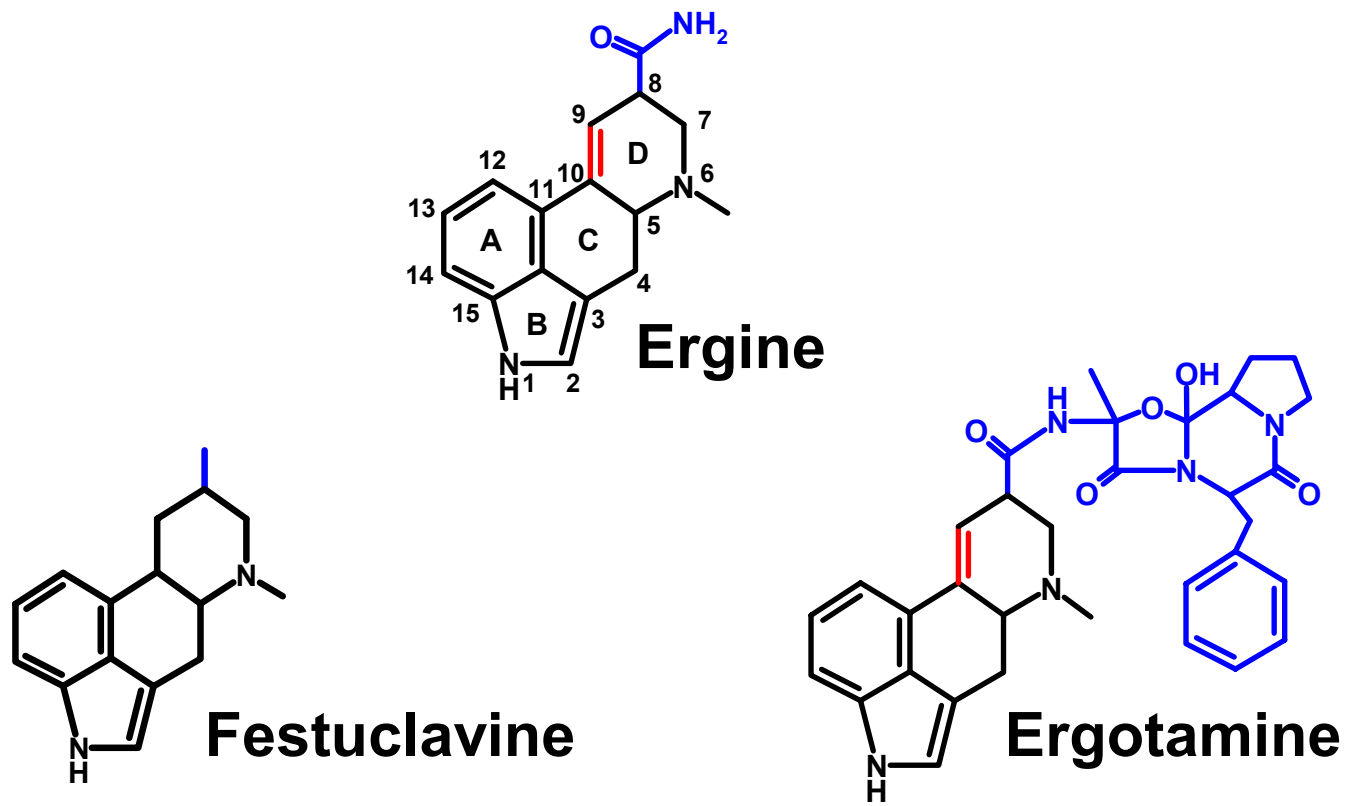

Obtained from Dr. Panaccione 


\section{FIGURE 2.}

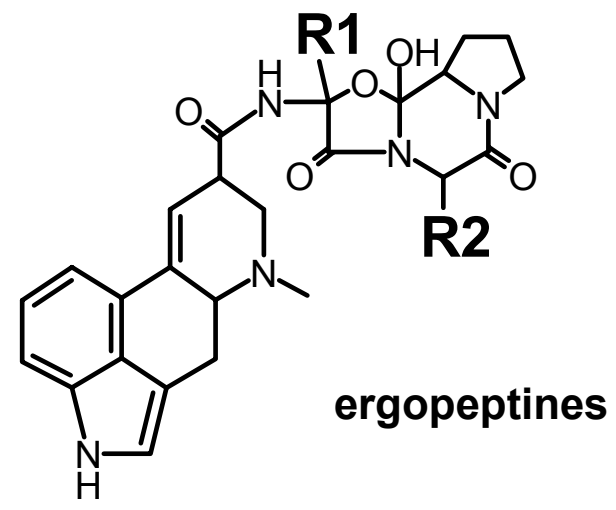

R1 = side chain for:

\begin{tabular}{|c|c|c|}
\hline & ala & val \\
\hline $\begin{array}{l}\text { val } \\
\text { leu } \\
\text { phe }\end{array}$ & $\begin{array}{l}\text { ergovaline } \\
\text { ergosine } \\
\text { ergotamine }\end{array}$ & $\begin{array}{l}\text { ergocornine } \\
\alpha \text {-ergocryptine } \\
\text { ergocristine }\end{array}$ \\
\hline
\end{tabular}

Obtained from Dr. Panaccione 


\section{FIGURE 3.}

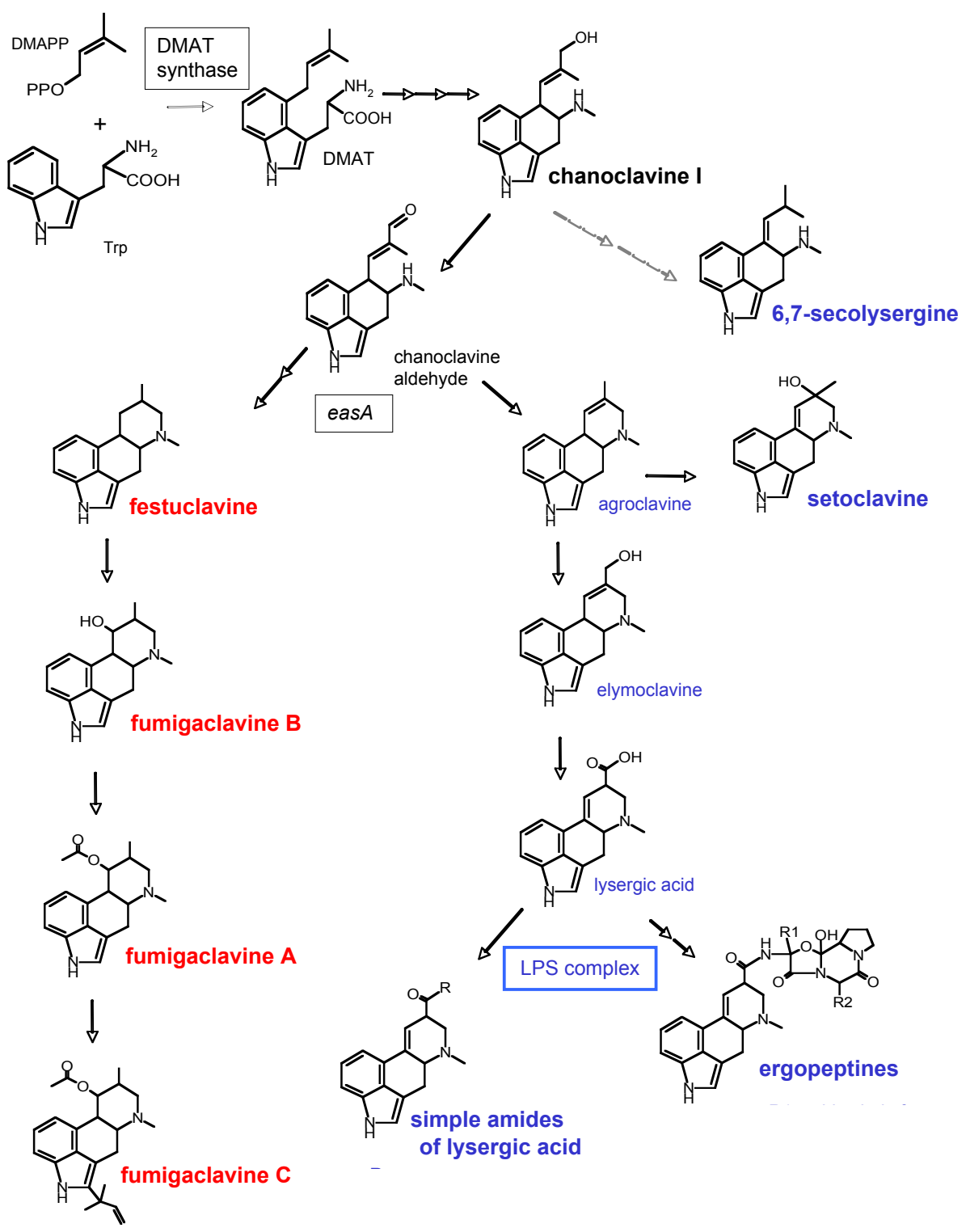

Aspergillus fumigatus

Clavicipitaceous fungi

Obtained from Dr. Panaccione 
CHAPTER-2 
Spatial expression patterns of ergot alkaloid genes during conidiophore development in Aspergillus

fumigatus 


\section{ABSTRACT}

Production of ergot alkaloids in the opportunistic fungal pathogen Aspergillus fumigatus is restricted to conidiating cultures, which typically accumulate several pathway intermediates at concentrations comparable to that of the pathway end product. I investigated the contribution of different cell types that constitute the multicellular conidiophore of $A$. fumigatus to the production of intermediates versus end product. Conidiating cultures (containing hyphae, vesicle of conidiophore, phialides of conidiophore, and conidia) accumulated more of the pathway intermediate festuclavine and less of the pathway end product fumigaclavine $\mathrm{C}$ than did isolated mature conidia. These data indicated differences in distribution or activity of ergot pathway enzymes. Such differences also were indicated by studies with conidiophore mutants. A medA mutant, which proliferates phialides, accumulated more pathway intermediates than did the wild type or a complemented medA mutant. A stuA mutant, lacking recognizable conidiophores, produced no detectable ergot alkaloids. Distribution of several ergot alkaloid pathway enzymes among different conidiophore cell types was investigated by labeling enzymes with autofluorescent proteins. Fluorescence associated with expression of each tested gene indicated a similar pattern of spatial expression. Fluorescence was not observed in young hyphae but was detected at the apices of hyphae as they swelled to form the vesicle of the conidiophore. More fluorescence was observed in mature vesicles, phialides, and conidia. No qualitative differences were observed in cell type-specific expression of different pathway genes, indicating that observed differences in accumulation of intermediates versus end product must be due to quantitative differences in expression or differences in activity of pathway enzymes. 


\section{INTRODUCTION}

Ergot alkaloids are a complex family of tri- or tetracyclic mycotoxins that are derived from prenylated tryptophan and have diverse structures and biological activities (Schardl et al., 2006; Lorenz et al., 2009; Panaccione, 2010). Because of their ability to act as partial agonists or antagonists at different adrenaline, dopamine, and serotonin receptors they affect nervous, circulatory, reproductive, and immune systems. Symptoms include reduced fertility, changes in blood pressure, lowered immune response, hallucinations, disturbances in sleep-wake cycles and gangrene of the limbs.

Several fungi, representing two distantly related orders (Eurotiales and Hypocreales) within the phylum Ascomycota produce ergot alkaloids (Schardl et al., 2006; Panaccione, 2010). The ergot alkaloids of $A$. fumigatus, a common saprophyte and opportunistic pathogen in the order Eurotiales, belong to the simpler class of clavine alkaloids and include chanoclavine, festuclavine, fumigaclavine $\mathrm{B}$, fumigaclavine A, and fumigaclavine C (Fig. 1) (Cole et al., 1977; Panaccione and Coyle, 2005). The synthesis of these alkaloids is controlled by specific genes in the ergot alkaloid pathway. Those that will be analyzed in the current study include the following: $d m a W$ which controls the first determinant step of the ergot alkaloid pathway (Coyle and Panaccione, 2005; Unsöld and Li, 2005); eas $C$ and eas $E$ which are required for the formation of chanoclavine (Lorenz et al., 2010; Goetz et al., 2011); easA which acts after chanoclavine and contributes to the formation of festuclavine (Cheng et al., 2010; Coyle et al., 2010); and, the last step of the pathway, which results in the formation of the end product fumigaclavine $\mathrm{C}$, is controlled by eas (Unsöld and Li, 2005).

Aspergillus fumigatus accumulates high concentrations of ergot alkaloids in or on 
conidia (Panaccione and Coyle, 2005). The ergot alkaloid pathway of $A$. fumigatus is relatively long and several pathway intermediates accumulate to levels approaching or exceeding that of the pathway end product, fumigaclavine C (Panaccione, 2005; Panaccione and Coyle, 2005). Thus the ergot pathway is considered inefficient because there is no rapid flow of intermediates into one final end product. A sporulating culture of A. fumigatus develops four morphologically distinguishable cell types: long tubular vegetative hyphae that grow in a polar fashion by apical extension; an aerial conidiophore stalk that develops from the hyphae and terminates with a bulbous vesicle; the phialide of conidiophore, which repeatedly produces conidia; and, the conidium (Timberlake, 1991). The restriction of ergot alkaloids to conidiating cultures has been established (Coyle et al., 2007), but the location of ergot alkaloid biosynthesis within those cultures is unknown. Moreover, the documented inefficiency in converting ergot alkaloid pathway intermediates may conceivably have a basis in differential distribution of pathway enzymes among conidiophore cell types. The objectives for this current study were to investigate potential differences in conidiophore cell-type specific production of ergot alkaloids by separating cell types (where possible), to study ergot alkaloid accumulation in conidiophore development mutants, and to determine the expression of ergot alkaloid pathway enzymes in specific cell types by tagging them with autofluorescent proteins.

\section{MATERIALS AND METHODS}

\section{Fungi and culture conditions}


Aspergillus fumigatus strain Af293 was used as the wild-type strain. Two different mutant strains derived from A. fumigatus Af293, $\Delta$ medA (Gravelat et al., 2010) and $\Delta$ stuA (Sheppard et al., 2005), also were studied. All A. fumigatus strains were cultured on potato dextrose agar [PDA; 20 g/L dehydrated potatoes (Idaho Spuds; Pillsbury, Minneapolis, MN), $20 \mathrm{~g} / \mathrm{L}$ glucose, $15 \mathrm{~g} / \mathrm{L}$ agar (Bacto agar; Difco, Detroit, MI)] at $37^{\circ} \mathrm{C}$. For protoplast preparation, the fungi were cultured overnight in $15 \mathrm{~mL}$ of malt extract medium (50 g/L malt extract, $50 \mathrm{~g} / \mathrm{L}$ lactose, $5 \mathrm{~g} / \mathrm{L}$ asparagine, and $0.4 \mathrm{~g} / \mathrm{L} \mathrm{K}_{2} \mathrm{HPO}_{4}$ ) in a deep Petri dish (depth, 20 mm; diameter, 100 mm; Fisher Scientific, Pittsburgh, PA) on an orbital shaker (150 rpm) at $37^{\circ} \mathrm{C}$. For fluorescent microscopy analysis, conidia from GFP-expressing A. fumigatus strains were inoculated on microscopic slides covered with glucose minimal medium (Shimizu and Keller, 2001) and incubated at $37^{\circ} \mathrm{C}$.

\section{Analysis of ergot alkaloids}

Ergot alkaloids were extracted from ten sporulating culture plates each of the wild type and mutant $A$. fumigatus strains that were grown at $37^{\circ} \mathrm{C}$ for five days. Agar plugs containing $50.3 \mathrm{~mm}^{2}$ of colony surface area (cut with the broader end of a disposable tip for a P1000 Pipetman) of the A. fumigatus cultures were crushed and extracted in 0.5 $\mathrm{ml}$ of $80 \%$ HPLC grade methanol as described by Coyle et al. (2007). Ergot alkaloids were quantified from $20 \mu \mathrm{L}$ of the supernatant by high-pressure liquid chromatography (HPLC) over a $\mathrm{C}_{18}$ column [Prodigy $5 \mu \mathrm{m}$ ODS3 (150 mm by $4.6 \mathrm{~mm}$ ); Phenomenex, Torrance, CA] with acetonitrile-ammonium acetate gradients and detected by fluorescence (excitation and emission wavelengths of $272 \mathrm{~nm}$ and $372 \mathrm{~nm}$, respectively) (Panaccione et al., 2003; Panaccione and Coyle, 2005). For spore versus whole culture ergot alkaloid analysis, the culture plates were first inverted and agitated to collect most 
of the conidia on the lid. Conidia were then suspended in methanol to extract alkaloids. After removing most of the conidia an agar plug from the same culture plate was suspended in methanol to analyze ergot alkaloids of the whole culture. The spore only and whole culture suspensions were aliquoted for ergot alkaloid analysis and enumeration of conidia. Spore counts were performed on spore only extracts and whole culture extracts and alkaloids were expressed on a per spore basis. Peaks of alkaloids chanoclavine, festuclavine, fumigaclavine $A$, fumigaclavine $B$, and fumigaclavine $C$ were detected based on methods employed in previous studies (Coyle and Panaccione, 2005; Coyle et al., 2010). Quantification of ergot alkaloids were based on comparison of peak areas to those of the external standard agroclavine as described previously (Panaccione and Coyle, 2005). Data from spore-only versus entire culture extracts were analyzed by application of the Wilcoxon / Kruskal-Wallis (rank sums) test and those from medA mutant strain were analyzed by ANOVA and, when appropriate, the TukeyKramer test. All analyses were performed with the JMP software package (SAS, Cary, NC).

\section{Generation of fluorescent protein tagged ergot alkaloid genes and transformation}

The intact ergot alkaloid genes $d m a W$, easE, easC, eas $A$ and eas $L$ which catalyze steps in the ergot pathway were amplified with their native promoters from wild-type strain Af293 with the primers listed in Table 1. All PCR reactions were performed on Bio-Rad C1000 ${ }^{\mathrm{TM}}$ Thermal cycler and included 5X PCR buffer (Promega, Madison, WI), $1.6 \mathrm{mM} \mathrm{MgCl}_{2}, 200 \mu \mathrm{M}$ dNTP, $1 \mu \mathrm{M}$ each primer, $0.2 \mu \mathrm{g}$ DNA and $1 \mathrm{U}$ GoTaq Flexi DNA polymerase (Promega). Final volume for each reaction was $50 \mu \mathrm{L}$. The standard PCR profile was as follows: 3 min at $94^{\circ} \mathrm{C}, 35$ cycles of 30 s at $94^{\circ} \mathrm{C}, 30$ s at annealing 
temperature, and $3 \mathrm{~min}$ at $72^{\circ} \mathrm{C}$, followed by a final extension of $5 \mathrm{~min}$ at $72^{\circ} \mathrm{C}$. The annealing temperature varied depending on the target (dmaW, 61.1; easE, 57.0; easC, 57.7; easA, 52.0; easL, 52.0). For $d m a W$, easE, and easA genes, the amplified fragments lacking the stop codon, were cloned in frame with Cycle 3 GFP of the pcDNA3.1/CT-GFP-TOPO expression vector from the CT-GFP Fusion TOPO® TA Expression Kit (Invitrogen, Carlsbad, CA), according to manufacturer's instructions. For easL, which catalyzes the final step of the ergot pathway, the gene lacking stop codon was amplified with gene specific primers and cloned as a BamHI-Agel fragment into a red fluorescent pDSRed2 vector from Clontech Laboratories, Inc. (Palo Alto, CA). The recombinant vector, pXFP $(X=d m a W$, easE, eas $A$ and easL $)$ allowed expression of ergot alkaloid genes with Cycle 3 GFP and RFP respectively fused at its C-terminus. For easC, a potential C-terminal peroxisomal signal (amino acid residues $S R L$ ) was observed, so an N-terminal GFP fusion plasmid [pXFP $(\mathrm{X}=$ eas $C)$ ] was constructed in order to prevent any interference of the GFP with the signal. The orientation of the insert and sequence of all the plasmids were confirmed by sequencing. Protoplasts were prepared and transformed as described by Coyle et al. (2010). Cotransformation of the protoplasts was performed with the linearized fluorescent protein fusion construct, pXFP, and a hygromycin resistance plasmid, pMOcosX (Orbach, 1994), that had been linearized at a unique Xhol site (Coyle et al., 2007). Colonies growing on the transformation plates were screened for the presence of pXFP construct by PCR assay with primers that were specifically designed to target fluorescent protein coding sequence. In case of easC-GFP, a second transformant was made in which the GFP construct was targeted to the ergot gene cluster. This was done to test whether the 
spatial pattern of expression was affected by the integration site of the GFP construct. Transformants were screened for homologous recombination of the plasmid peasCFP with the primer easCScrnF, which anneals to $5^{\prime}$ end of the easC gene and flanking the targeted site of integration and easCScrnR which anneals specifically to vector sequence (Table 1). Transformants yielding a fragment of $0.7 \mathrm{~kb}$ for homologous recombination at easC were purified to nuclear homogeneity along with transformants that had ectopic integration of eas $C$ by culturing them from individual, germinated conidia. Single spore colonies were again screened by PCR for the presence of pXFP fusion construct.

\section{Microscopic techniques}

Colonies of strains expressing GFP were visualized by a Nikon Eclipse TE2000-S inverted microscope (Nikon, Tokyo, Japan) equipped with a $100 \mathrm{~W}$ mercury vapor lamp. Green and red filter sets were used to detect the GFP and RFP proteins, respectively. Pictures were taken with a Q Imaging Retiga 2000R camera equipped with Qcapture 2.90.1 software (Quantitative Imaging Corporation, Surrey, British Columbia, Canada) and processed with Adobe Photoshop CS5 (Adobe Systems Inc., San Jose, CA).

\section{RESULTS}

\section{Ergot alkaloid content of whole sporulating cultures compared to mature,} abscised conidia

Cultures of wild-type A. fumigatus contained morphologically distinct cell types: vegetative hyphae, stalk with vesicle of conidiophore, phialides of conidiophore, and conidia. Samples from the entire culture (and thus containing all the four cell types) 
contained an average of $3.3 \mathrm{fg}$ of total ergot alkaloids per conidium, whereas samples made up exclusively of mature abscised conidia contained an average of $1.2 \mathrm{fg}$ of total ergot alkaloids per conidium, indicating that cell types other than conidia contributed to the ergot alkaloid yield of the whole cultures. The difference in accumulation of total ergot alkaloids per spore between whole cultures (made up of different cell types) as compared to isolated, mature conidia was statistically significant $(P=0.002)$. The proportion of festuclavine (the intermediate that accumulates to the highest concentrations) relative to total ergot alkaloids extracted was significantly greater in whole-culture extracts than in mature spore extracts $(P=0.0002)$ (Fig. 2). The converse was true for the three alkaloids downstream from festuclavine, fumigaclavine $B$ $(P=0.0002)$, fumigaclavine $\mathrm{A}(P=0.0025)$, and fumigaclavine $\mathrm{C}(P=0.0002)$ (Fig. 2$)$.

\section{Ergot alkaloid profiles of wild type, and $\Delta s t u A$ and $\Delta m e d A$ mutants and their}

\section{complemented derivatives}

The $\Delta$ stuA mutant strain of $A$. fumigatus, lacking vesicles and phialides (Sheppard et al., 2005), contained no detectable ergot alkaloids, and the corresponding complemented strain had a profile similar to that of the wild type (data not shown). In contrast, conidiating colonies of the $\Delta m e d A$ mutant strain, which has multiple layers of phialides (Gravelat et al., 2010), accumulated higher amounts of total ergot alkaloids per conidium than did the wild-type $(P=0.03)$. However, levels of the end product of the pathway (fumigaclavine $\mathrm{C}$ ) were not significantly different in the $\Delta m e d A$ mutant and wild-type ( $P=0.33)$ (Fig. 3A). The medA mutant, in comparison to the wild type, accumulated a significantly higher proportion of combined pathway intermediates (chanoclavine, festuclavine, fumigaclavine $B$, and fumigaclavine $A$ ) compared to levels 
of pathway end product (fumigaclavine $C)(P<0.0001)$ (Fig. 3B).

Spatial localization of ergot alkaloid pathway genes during conidiophore development

Ergot pathway gene products were observed at different time points in order to capture their localization patterns in all the asexual development stages of $A$. fumigatus.

Fluorescence was not detected during the vegetative growth of the fungus and was first observed during conidiophore development. Similar spatial localization patterns were observed for all the genes tested in the study. In young conidiophores, the fluorescence was not randomly distributed but rather visualized as localized near the tip of the developing conidiophore (Fig. 4 A, E, I, M, Q) and to the zone that later became the phialide-bearing region of the conidiophore vesicle (Fig. 4 B, F, J, N, R). Extensive fluorescence was observed in the mature phialides that developed from the vesicle (Fig. $4 \mathrm{C}, \mathrm{G}, \mathrm{K}, \mathrm{O}, \mathrm{S})$. Fluorescence was also observed in the conidia that developed from the mature phialides (Fig. $4 \mathrm{D}, \mathrm{H}, \mathrm{L}, \mathrm{P}, \mathrm{T}$ ). In the case of easL-RFP expressing $A$. fumigatus strain, greater fluorescence was observed in conidia relative to conidiophores (Compare Fig. $4 \mathrm{~T}$ and $\mathrm{S}$ ) when compared to the relative fluorescence of conidia versus conidiophores of any of the other fluorescently labeled enzymes. The non-transformed wild-type strain did not fluoresce under the same observation conditions (data not shown). There was no difference in the expression patterns between the ectopic and cluster integrated easC-GFP expressing A. fumigatus strains (data not shown).

\section{DISCUSSION}


Results from this study have provided new information on the developmental regulation of ergot alkaloid biosynthesis in A. fumigatus. Comparative alkaloid analysis of entire sporulating culture extracts and a spore only extracts demonstrated that ergot alkaloids are in fact produced in cell types that constitute a developing conidiophore in addition to the conidia of $A$. fumigatus. This was further confirmed by analysis of different cell-type mutants. The "medusa" mutant $(\Delta \operatorname{med} A)$, which has an abnormal phenotype with excess phialides and fewer conidia than wild-type (Gravelat et al., 2010), showed higher accumulation of pathway intermediates when compared to end products of the pathway. The "stunted" mutant $(\Delta s t u A)$ with no vesicle or phialides and very few conidia (Sheppard et al., 2005) did not produce any detectable ergot alkaloids. Although this mutant produces very few conidia, the number of conidia extracted from the samples would have yielded ergot alkaloids at concentrations of at least 200-times the detection threshold if they contained alkaloids typical of wild-type conidia. These results raised the question of whether the pathway inefficiency that leads to differential accumulation of ergot alkaloids is due to cell-type specific expression of ergot alkaloid genes.

Autofluorescent protein expression studies of different ergot alkaloid pathway genes showed no detectable fluorescence in vegetative hyphae, supporting the hypothesis that these alkaloids are produced only during sporulation as opposed to during vegetative growth of the fungus (Coyle et al., 2007; Twumasi-Boateng et al., 2009). Fluorescence was initially localized to the tips of hyphae that were differentiating into conidiophores; it was observed to be more evenly distributed in subsequent cell types. Spatial expression patterns were observed for all tested ergot alkaloid genes in specific cell types of the multicellular conidiophore, but no clear qualitative cell-type 
specific differences in the expression of individual genes were detected. This suggests that quantitative differences in the expression of these genes in each cell type could account for the observed differential accumulation of intermediates versus end product of the ergot alkaloids pathway. Greater fluorescence of the easL-RFP construct was observed in conidia relative to conidiophores compared to the relative fluorescence of conidia versus conidiophores of any of the other fluorescently labeled enzymes. Whereas this difference is apparent from comparing the relevant panels in Fig. 4, definitive conclusions cannot be made because quantifying the fluorescence from different cell types is extremely difficult due to the close association of those cell types. Elevated expression of the reverse prenyl transferase encoded by eas $L$ in conidia as compared to conidiophores result in accumulation of end product fumigaclavine $C$ to higher concentration in conidia.

Recent evidence from knock-out studies and transcriptome analysis have indicated that all ergot alkaloid genes of $A$. fumigatus are regulated by trans-acting transcription factors such as brlA and stuA (Coyle et al., 2007; Twumasi-Boateng et al., 2009). Moreover, it has been shown that genes that are targeted by similar transcription factors are co-expressed (Marco et al., 2009). This may explain the overall similar spatial patterns of expression observed in case of all tested ergot alkaloid genes. Furthermore, in this study many of the GFP-fused ergot alkaloid gene constructs integrated ectopically in the genome; since these ergot alkaloid genes are regulated by trans-acting transcription factors, the effect of position in the genome should be minimal. This hypothesis is supported by the observations from the ectopic and cluster integrated easC-GFP expressing $A$. fumigatus strains. 
In conclusion, the ergot alkaloid pathway of $A$. fumigatus functions differently in different cell types associated with conidiation, resulting in higher concentrations of intermediates in extracts containing all cell types of conidiating cultures and higher concentration of end product in mature, abscised conidia. Several ergot alkaloid cluster genes are expressed in all cell types that constitute the mature conidiophore of $A$. fumigatus. Thus, pathway inefficiency which leads to higher accumulation of intermediates in certain cell types is not due to qualitative cell typespecific expression of ergot alkaloid genes. However, the possibility that quantitative differences in expression of eas $L$ result in accumulation of the end product fumigaclavine $\mathrm{C}$ in conidia more than in conidiophores was supported by observation.

\section{ACKNOWLEDGMENTS}

This work was supported by grant number 2008-35318-04549 from the United States Department of Agriculture, National Institute of Food and Agriculture, and published with permission of the West Virginia Agriculture and Forestry Experiment Station as scientific article number (supplied upon acceptance). I thank Dr. Christine Coyle for performing the alkaloid analysis of the whole culture to mature conidia, Natalie A. Allen for the comparative alkaloid analysis of the wild type A. fumigatus, medA and stuA mutants, Drs. Don Sheppard and Fabrice Gravalat, McGill University, for providing medA and stuA mutants, Dr. Jianbo Yao, West Virginia University for use of his epifluorescence microscope and Dr. Rittenour, National Institute for Occupational Safety and Health for helpful discussions. 


\section{REFERENCES}

Cheng, J.Z., Coyle, C.M., Panaccione, D.G., O'Connor, S.E. 2010. Controlling a structural branch point in ergot alkaloid biosynthesis. J Am Chem Soc 132, 1283512837.

Cole, R., Kirksey, J., Dorner, J., Wilson, D., Johnson Jr, J., Johnson, A., Bedell, D., Springer, J., Chexal, K. 1977. Mycotoxins produced by Aspergillus fumigatus species isolated from molded silage. J Agric Food Chem 25, 826-830.

Coyle, C.M., Cheng, J.Z., O'Connor, S.E., Panaccione, D.G. 2010. An old yellow enzyme gene controls the branch point between Aspergillus fumigatus and Claviceps purpurea ergot alkaloid pathways. Appl Environ Microbiol 76, 3898-3903.

Coyle, C.M., Kenaley, S.C., Rittenour, W.R., Panaccione, D.G. 2007. Association of ergot alkaloids with conidiation in Aspergillus fumigatus. Mycologia 99, 804-811.

Coyle, C.M., Panaccione, D.G. 2005. An ergot alkaloid biosynthesis gene and clustered hypothetical genes from Aspergillus fumigatus. Appl Environ Microbiol 71, 3112-3118.

Goetz, K.E., Coyle, C.M., Cheng, J.Z., O'Connor, S.E., Panaccione, D.G., 2011. Ergot cluster-encoded catalase is required for synthesis of chanoclavine-I in Aspergillus fumigatus. Curr Genet. 57, 201-211.

Gravelat, F.N., Ejzykowicz, D.E., Chiang, L.Y., Chabot, J.C., Urb, M., Macdonald, K.D., al-Bader, N., Filler, S.G., Sheppard, D.C. 2010. Aspergillus fumigatus MedA governs adherence, host cell interactions and virulence. Cell Microbiol 12, 473-488.

Lorenz, N., Haarmann, T., Pazoutová, S., Jung, M., Tudzynski, P. 2009. The ergot alkaloid gene cluster: functional analyses and evolutionary aspects. Phytochemistry 70 , $1822-1832$. 
Lorenz, N., Olsovská, J., Sulc, M., Tudzynski, P. 2010. Alkaloid cluster gene ccsA of the ergot fungus Claviceps purpurea encodes chanoclavine I synthase, a flavin adenine dinucleotide-containing oxidoreductase mediating the transformation of $\mathrm{N}$-methyldimethylallyltryptophan to chanoclavine I. Appl Environ Microbiol 76, 1822-1830. Marco, A., Konikoff, C., Karr, T.L., Kumar, S. 2009. Relationship between gene coexpression and sharing of transcription factor binding sites in Drosophila melanogaster. Bioinformatics 25, 2473-2477.

Orbach, M.J. 1994. A cosmid with a HyR marker for fungal library construction and screening. Gene 150, 159-162.

Panaccione, D. 2010. Ergot Alkaloids. The Mycota 10, 195-214.

Panaccione, D.G., 2005. Origins and significance of ergot alkaloid diversity in fungi. FEMS Microbiol Lett 251, 9-17.

Panaccione, D.G., Coyle, C.M. 2005. Abundant respirable ergot alkaloids from the common airborne fungus Aspergillus fumigatus. Appl Environ Microbiol 71, 3106-3111. Panaccione, D.G., Tapper, B.A., Lane, G.A., Davies, E., Fraser, K. 2003. Biochemical outcome of blocking the ergot alkaloid pathway of a grass endophyte. J Agric Food Chem 51, 6429-6437.

Schardl, C.L., Panaccione, D.G., Tudzynski, P. 2006. Ergot alkaloids--biology and molecular biology. Alkaloids Chem Biol 63, 45-86.

Sheppard, D.C., Doedt, T., Chiang, L.Y., Kim, H.S., Chen, D., Nierman, W.C., Filler, S.G. 2005. The Aspergillus fumigatus StuA protein governs the up-regulation of a discrete transcriptional program during the acquisition of developmental competence. Mol Biol Cell 16, 5866-5879. 
Shimizu, K., Keller, N.P. 2001. Genetic involvement of a cAMP-dependent protein kinase in a G protein signaling pathway regulating morphological and chemical transitions in Aspergillus nidulans. Genetics 157, 591-600.

Timberlake, W.E. 1991. Temporal and spatial controls of Aspergillus development. Curr Opin Genet Dev 1, 351-357.

Twumasi-Boateng, K., Yu, Y., Chen, D., Gravelat, F.N., Nierman, W.C., Sheppard, D.C. 2009. Transcriptional profiling identifies a role for $B r l A$ in the response to nitrogen depletion and for StuA in the regulation of secondary metabolite clusters in Aspergillus fumigatus. Eukaryotic Cell 8, 104-115.

Unsöld, I.A., Li, S.-M. 2005. Overproduction, purification and characterization of FgaPT2, a dimethylallyltryptophan synthase from Aspergillus fumigatus. Microbiology $151,1499-1505$. 


\section{FIGURE LEGENDS}

Figure 1. Ergot alkaloid biosynthetic pathway of $A$. fumigatus. Multiple arrows indicate omitted intermediates. Steps catalyzed by genes included in the current study are indicated.

Figure 2. Proportion of individual ergot alkaloids relative to the total ergot alkaloids extracted in a sporulating culture containing all cell-types (black bars) vs samples of abscised conidia (grey bars). A significant difference $(P<0.05)$ was found when comparing each ergot alkaloid between sample types with the nonparametric Wilcoxon / Kruskal-Wallis rank sum test. Error bars represent standard error. The insert represents a magnified view (note scale on $\mathrm{Y}$ axis) of proportions of fumigaclavine $\mathrm{A}$ and $\mathrm{B}$.

Figure 3. Ergot alkaloid content of $\Delta m e d A$ mutant versus wild-type A. fumigatus. (A) Total ergot alkaloids (black bars) and pathway end product fumigaclavine C (grey bars) among wild-type, $\Delta m e d A$ mutant, and $\Delta m e d A$ complemented strain. (B) Ratio of ergot alkaloid pathway intermediates (sum of chanoclavine, festuclavine, fumigaclavine A, and fumigaclavine $\mathrm{B}$ ) to end product (fumigaclavine $\mathrm{C}$ ) in wild type, $\Delta m e d A$ mutant, and $\Delta m e d A$ complemented strain. Standard error is shown by the error bars. Strains labeled with the same letter do not differ significantly according to the Tukey-Kramer honestly significant difference test $(P<0.05)$.

Figure 4. Spatial localization pattern of different ergot alkaloid genes of $A$. fumigatus during conidiophore development. Representative DIC and fluorescent images are 
provided for strains expressing fluorescent protein tagged dmaW, easC, easE, easA, and eas $L$ ergot alkaloid pathway genes (A-T). Fluorescence localized to the tip of conidiophore stalk (fluorescence panel associated with $A, E, I, M$, and Q), the upper part of the vesicle that eventually becomes the phialide bearing region (fluorescence panel associated with $\mathrm{B}, \mathrm{F}, \mathrm{J}, \mathrm{N}$, and $\mathrm{R}$ ), phialides of the conidiophore (fluorescence panel associated with $\mathrm{C}, \mathrm{G}, \mathrm{K}, \mathrm{O}$, and $\mathrm{S}$ ), and conidia formed on mature conidiophores (fluorescence panel associated with D, H, L, P, and T). All images were captured under similar exposure time (1.98 s). Bar, $10 \mu \mathrm{m}$. 
TABLE 1. Primers used in this study. F, forward primer; $R$, reverse primer.

\begin{tabular}{|c|c|c|c|c|c|}
\hline $\begin{array}{l}\text { Target } \\
\text { gene }\end{array}$ & $\begin{array}{l}\text { Size } \\
\text { (bp) }\end{array}$ & $\begin{array}{l}\text { 5' UTR }^{\prime} \\
\text { (bp) }\end{array}$ & $\begin{array}{l}\text { 3' UTR } \\
\text { (bp) }\end{array}$ & $\begin{array}{l}\text { Primer } \\
\text { name }\end{array}$ & Sequence $5^{\prime}-3^{\prime}$ \\
\hline$d m a W$ & 2300 & 783 & - & $\begin{array}{l}\text { dmaW-F } \\
\text { dmaW-R }\end{array}$ & $\begin{array}{l}\text { GAGTGGTGTTGAGAGCTG } \\
\text { CCCAC } \\
\text { GGTGGAGACCGGAATAAT } \\
\text { ATACCC }\end{array}$ \\
\hline easC & 3358 & 1072 & 644 & $\begin{array}{l}\text { easC-F } \\
\text { easC-R }\end{array}$ & $\begin{array}{l}\text { TGAACAGCTCGGGACTTAC } \\
\text { TTC } \\
\text { CAGCAGATGGAGCAAGTG } \\
\text { ACTT }\end{array}$ \\
\hline easE & 2619 & 650 & - & $\begin{array}{l}\text { easE-F } \\
\text { easE-R }\end{array}$ & $\begin{array}{l}\text { GAGAGTCATCTTGGATAAG } \\
\text { GGC } \\
\text { GGCGGTATACCCGCTGGG } \\
\text { CAATGC }\end{array}$ \\
\hline eas $A$ & 1915 & 787 & - & $\begin{array}{l}\text { easA-F } \\
\text { easA-R }\end{array}$ & $\begin{array}{l}\text { GTGCGGAGTGCCTACTCTA } \\
\text { TAG } \\
\text { GGACGGGGAAATTATGCA } \\
\text { ATGC }\end{array}$ \\
\hline eash & 2089 & 729 & - & $\begin{array}{l}\text { easL-F } \\
\text { easL-R }\end{array}$ & $\begin{array}{l}\text { GACGGATCCTTATTAGAGA } \\
\text { AGATGCTCTAAGTGG } \\
\text { GCAACCGGTGGAAAGACG } \\
\text { GGTCGTGGCCCGCTG }\end{array}$ \\
\hline GFP & 719 & & & $\begin{array}{l}\text { gfp-F } \\
\text { gfp-R }\end{array}$ & $\begin{array}{l}\text { GCAGAATTCATGGCTAGCA } \\
\text { AAGGAGAAGAAC } \\
\text { GCAGAATTCTTTGTAGAGC } \\
\text { TCATCCATGCC }\end{array}$ \\
\hline easC & 746 & & & $\begin{array}{l}\text { easCScrnF } \\
\text { easCScrnR }\end{array}$ & $\begin{array}{l}\text { GGGCTATGGTGAAGGATG } \\
\text { CTTCC } \\
\text { CGGTCGCGGGATCGCGGG } \\
\text { CGAGG }\end{array}$ \\
\hline
\end{tabular}




\section{FIGURE 1.}

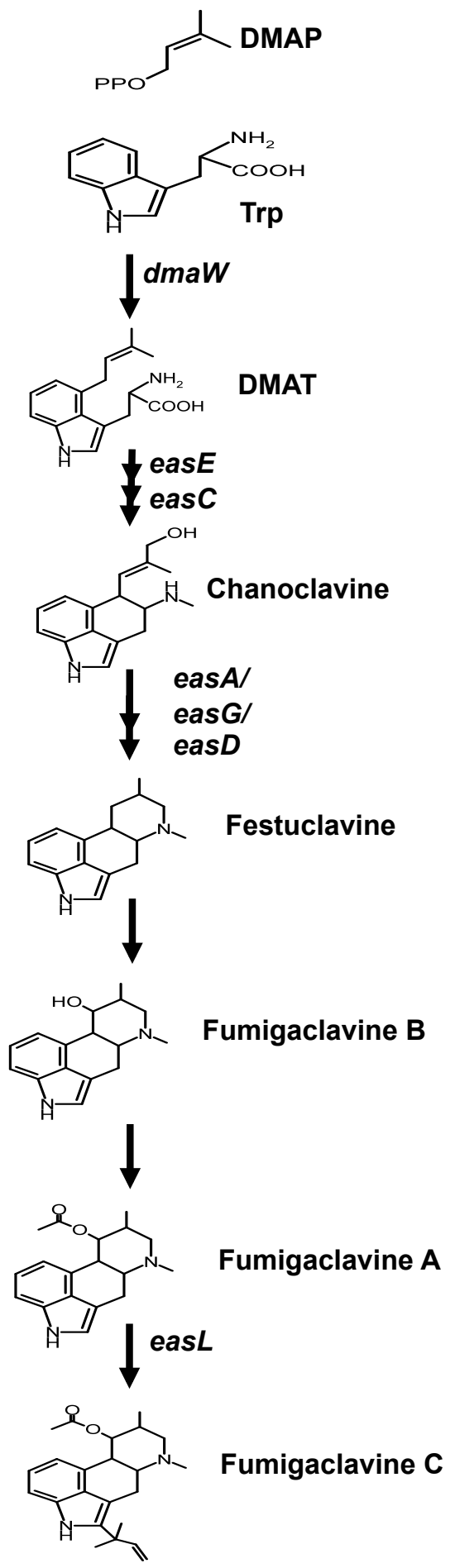




\section{FIGURE 2.}

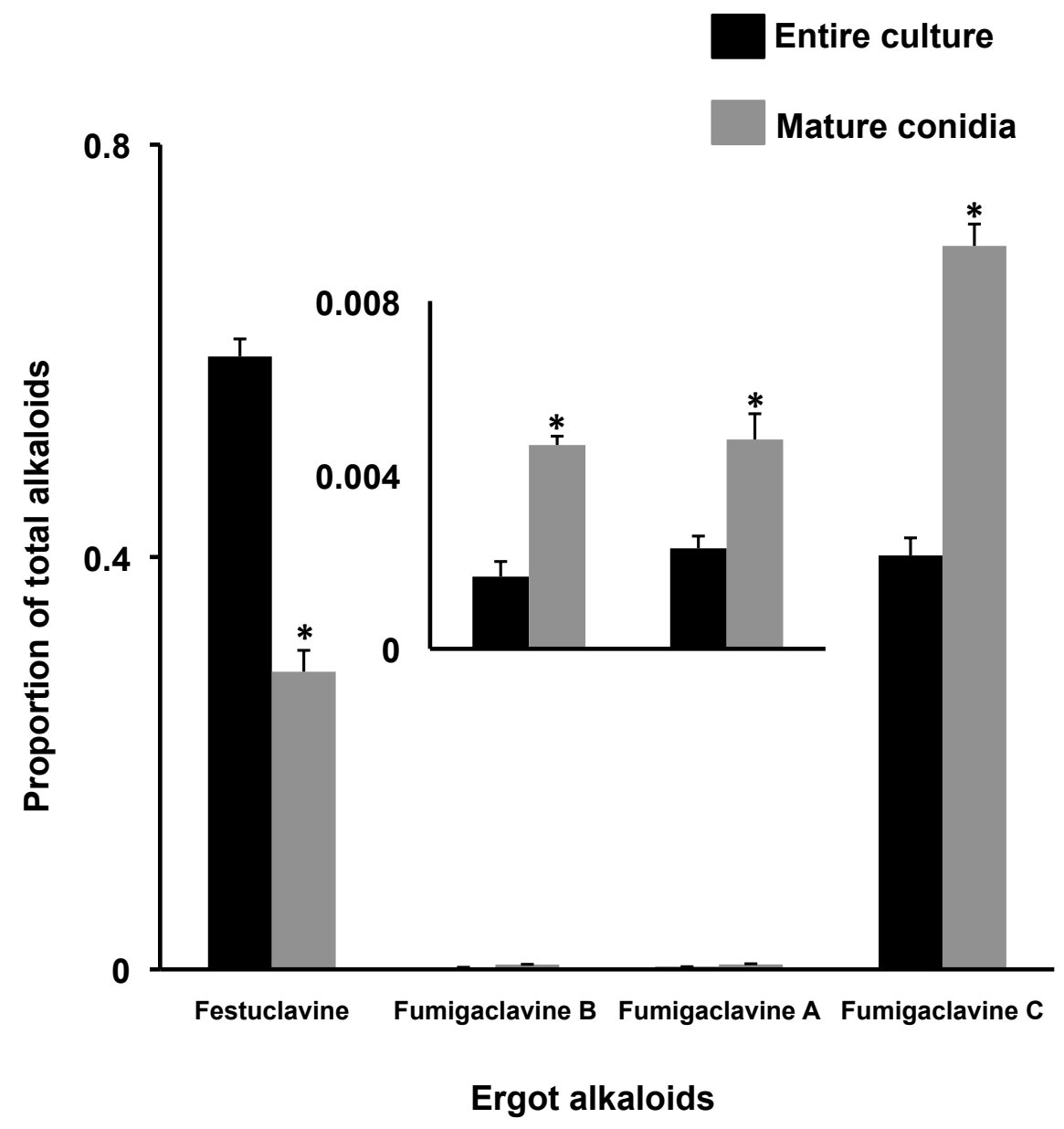


FIGURE 3.
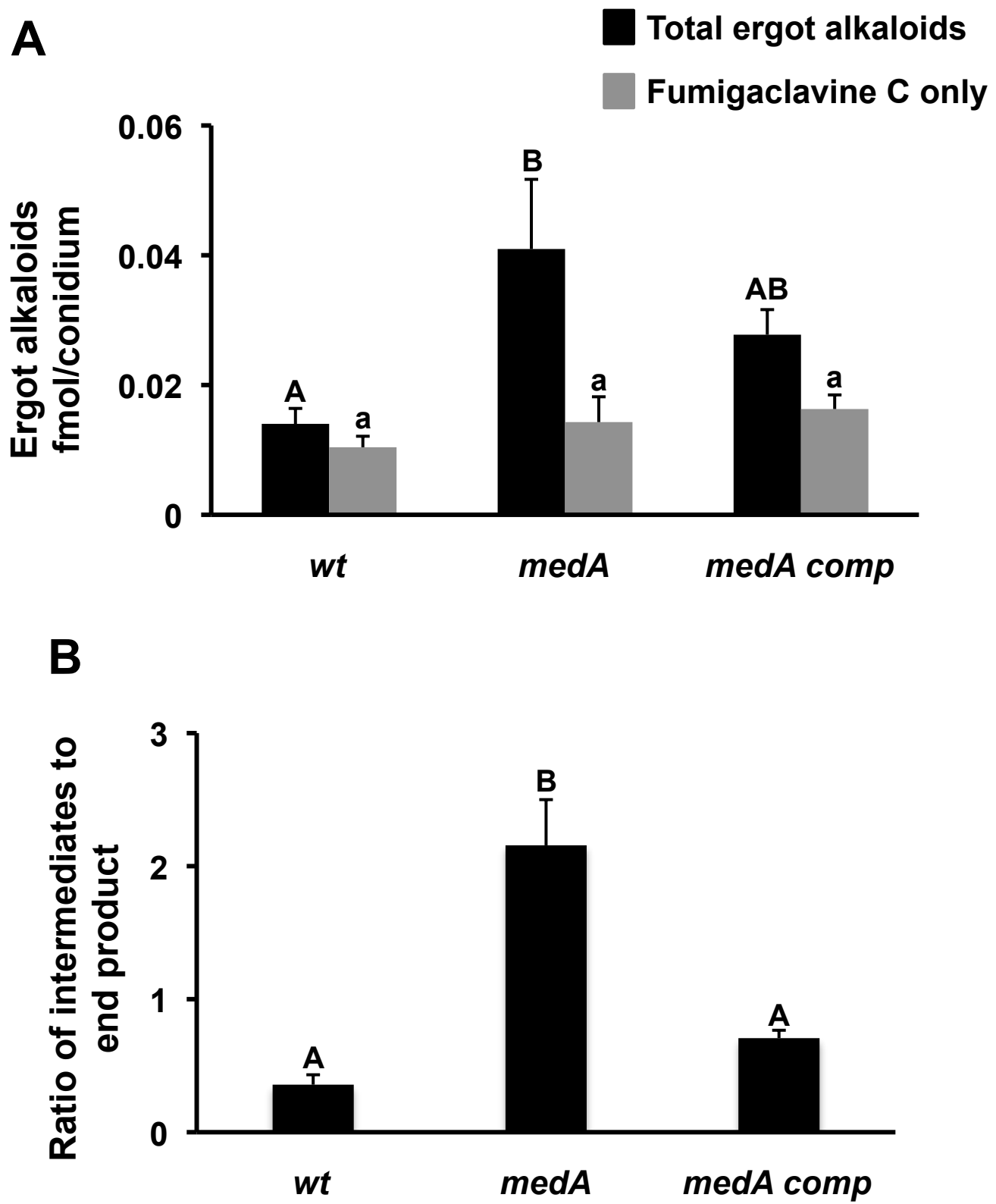
FIGURE 4.

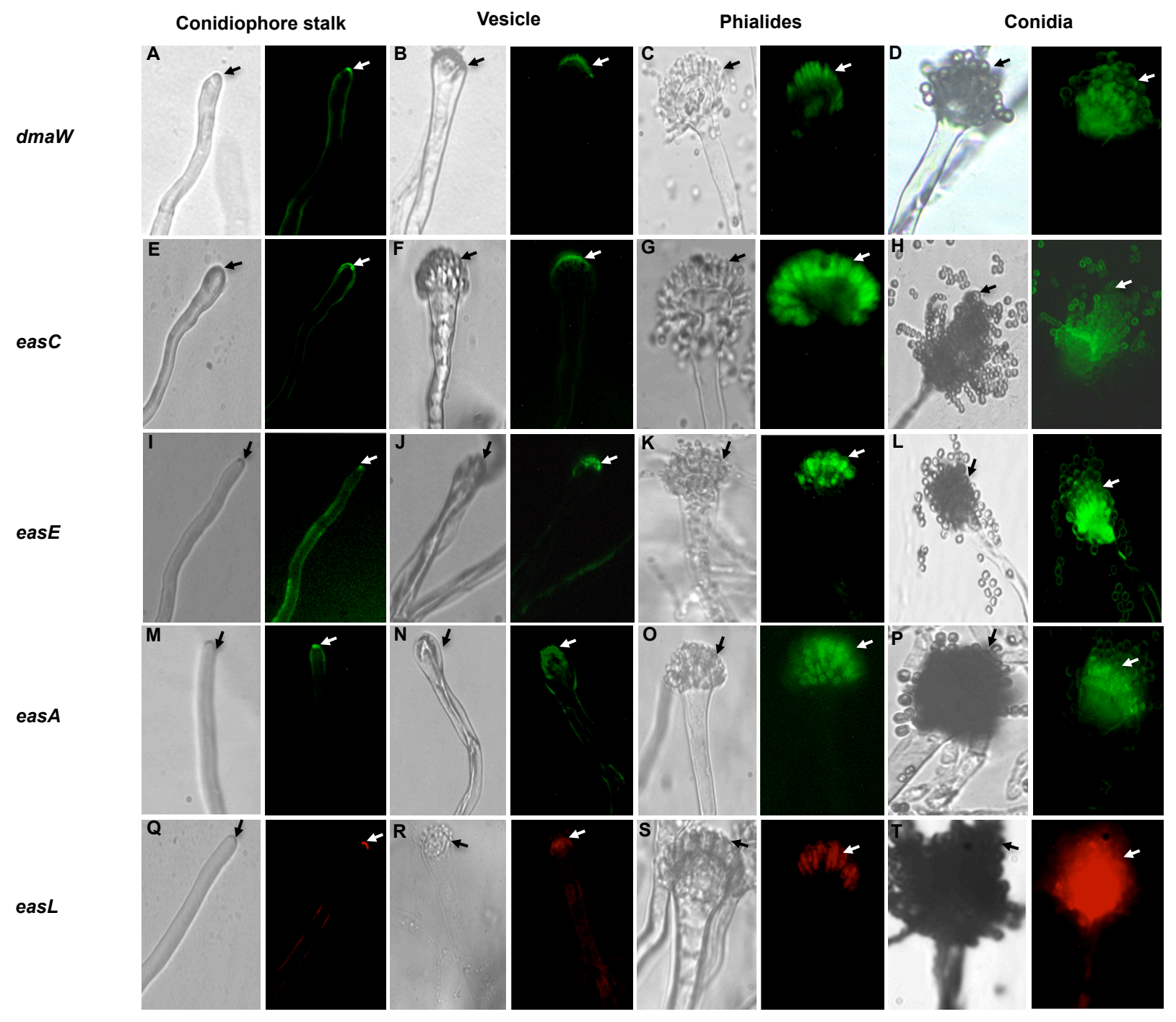


CHAPTER-3 
Investigation and genetic modification of ergot alkaloid pathway efficiency of Neotyphodium Iolii x Epichloë typhina isolate Lp1 (Neotyphodium sp. Lp1) 


\section{ABSTRACT}

The ergot alkaloid pathway of Neotyphodium Iolii × Epichloë typhina isolate Lp1

(Neotyphodium sp. Lp1), an endophytic symbiont of perennial ryegrass, is considered highly inefficient because of high accumulation of several pathway intermediates and shunt products in addition to the pathway end product. I investigated if pathway efficiency varied by tissue. My results demonstrated that different tissues of the host plant accumulated different profiles of ergot alkaloids as well as different total concentrations, indicating a potential tissue specific variation of expression of ergot pathway genes. Alteration of the expression of the ergot alkaloid pathway gene easA by RNA interference (RNAi) and over-expression techniques resulted in genetic manipulation of the flux of metabolites down the pathway. When compared to wild type, knock-down of eas $A$ resulted in higher accumulation of pathway intermediate chanoclavine and shunt product 6,7-secolysergine in comparison to pathway end product ergovaline. In contrast, over-expression of easA resulted in higher pathway ergovaline accumulation and no significant difference in the accumulation of intermediates and shunt products of the pathway. Collectively, my results indicate that ergot pathway genes are regulated differently in different tissues resulting in different profiles of ergot alkaloids. Also in Neotyphodium sp. Lp1, the concentration of easA mRNA has a significant role in controlling the efficiency in the flow of intermediates down the ergot alkaloid pathway. 


\section{INTRODUCTION}

Ergot alkaloids are mycotoxins that are derived from prenylated tryptophan and have varied biological activities (Schardl et al., 2006). They have been implicated in human toxicoses since medieval times. Toxic effects such as lowered immune responses, changes in blood pressure, hallucinations, gangrene of the limbs, reduced reproductive capability, and disturbances in sleep-wake cycle are caused by the ability of these alkaloids to act as partial agonists or antagonists at various serotonin, dopamine, and aadrenaline receptors (Goetz and Diederich, 1992; Pertz and Eich, 1999; Ganetsky and Brush, 2005). Several fungi, representing two distantly related orders, Eurotiales and Hypocreales, within the phylum Ascomycota produce ergot alkaloids (Schardl et al., 2006; Panaccione, 2010). Within the Hypocreales, they have been most extensively studied in the clavicipitaceous genera Claviceps and several fungi in the genera Epichloë and Neotyphodium, which live as endophytic symbionts in grasses (Schardl et al., 2006; Panaccione, 2010).

Neotyphodium spp. form symbiotic associations with cool-season grasses, such as tall fescue and perennial ryegrass, in which they grow in the intercellular spaces and colonize extensively at the base of the pseudostem. These endophytes are completely reliant on their host plant for existence and are transmitted only vertically via infected seeds (Clay and Schardl, 2002; Malinowski and Belesky, 2006). Neotyphodium spp. impart many significant traits to their host plants including tolerance to various biotic and abiotic stress factors and increased resistance to herbivores. They have also been associated with increases in tiller number, seed production, and root growth (Bush et al., 1997; Schardl and Phillips, 1997; Clay and Schardl, 2002; Panaccione, 2005; 
Malinowski and Belesky, 2006). In spite of their positive impact on the grasses, Neotyphodium spp. endophytes often are considered undesirable because of their negative effects on livestock. They often cause livestock toxicosis which is at least in part attributed to the ergot alkaloids that they produce (Hill et al., 1994; Filipov et al., 1998; Gadberry et al., 2003).

The ergot alkaloid pathway (Fig. 1) is relatively long and results in not just one final pathway end product but rather a mixture of end product, one or more intermediates, which accumulate to high concentrations, and alternate products that are produced by short shunt pathways off of the main pathway (Panaccione, 2005). These shunt pathways may influence pathway flux or accumulation of intermediates through the main pathway along with the production of additional products which results in the varied ergot alkaloid profile (Panaccione, 2005). So, the ergot alkaloid pathway is considered inefficient because there is reduced direct flow of intermediates into the final end product. Neotyphodium Iolii × Epichloë typhina isolate Lp1 (Schardl et al., 1994), an endophyte of perennial ryegrass, produces a wide range of ergot alkaloids including clavines, ergopeptines, and simple amides of lysergic acid. In particular, Neotyphodium sp. Lp1, accumulates relatively high concentrations of the clavines chanoclavine and 6,7-secolysergine and the ergopeptine ergovaline (Panaccione et al., 2003; Panaccione et al., 2006). Apart from these, it also accumulates ergine and lysergyl alanine as byproducts of ergopeptine synthesis. Based on studies with animal models and knockout endophytes, it has been demonstrated that the pathway inefficiency provides an advantage to the producing fungus and its plant host because both clavines and 
lysergic acid derivatives provide benefits to the host plant (Panaccione et al., 2006; Potter et al., 2008).

The objectives of this study were to investigate the potential reasons behind pathway inefficiency, determine if pathway efficiency varies between different tissues, and to manipulate the flow of metabolites through the ergot alkaloid pathway by altering the expression of easA employing RNA interference (RNAi) and overexpression strategies.

\section{MATERIALS AND METHODS}

\section{Fungi and growth conditions.}

Neotyphodium sp. Lp1 was cultured on potato dextrose agar (PDA; $20 \mathrm{~g} / \mathrm{L}$ dehydrated potatoes (Idaho Spuds; Pillsbury, Minneapolis, MN), 20 g/L glucose, $15 \mathrm{~g} / \mathrm{L}$ agar [Bacto agar; Difco, Detroit, MI]) at $20^{\circ} \mathrm{C}$. For protoplast preparation, the fungus was cultured for seven days in $50 \mathrm{~mL}$ of potato dextrose broth (PDB) in a $250 \mathrm{ml}$ flask on an orbital shaker $(200 \mathrm{rpm})$ at $20^{\circ} \mathrm{C}$.

\section{Construction of easA RNAi and overexpression vectors.}

A standard PCR strategy was employed to generate RNAi and overexpression constructs. All PCR reactions included: 5X PCR buffer (Promega, Madison, WI) with no magnesium, $1.6 \mathrm{mM} \mathrm{MgCl}_{2}, 200 \mu \mathrm{M}$ dNTP, $1 \mu \mathrm{M}$ each primer, $0.2 \mu \mathrm{g}$ DNA (from Neotyphodium sp. Lp1) and $1 \mathrm{U}$ GoTaq Flexi DNA polymerase (Promega) in a $50 \mu \mathrm{L}$ final volume. The standard PCR profile for all reactions was as follows: $3 \mathrm{~min}$ at $94^{\circ} \mathrm{C}$, 35 cycles of $30 \mathrm{~s}$ at $94^{\circ} \mathrm{C}, 30 \mathrm{~s}$ at $56^{\circ} \mathrm{C}$ and $3 \mathrm{~min}$ at $72^{\circ} \mathrm{C}$, followed by a final extension of 5 min at $72^{\circ} \mathrm{C}$. All primers used to generate these constructs are listed in Table 1. Generation of easA RNAi construct: 
Using primers RNAi-1F and RNAi-2R, a DNA fragment was amplified containing $450 \mathrm{bp}$ eas $A$ coding sequence, followed by $11 \mathrm{bp}$ of an intron sequence from eas $G$ gene that was artificially engineered into the reverse primer because eas $A$ lacks any natural introns. In a second PCR with primers RNAi-3F and RNAi-4R, a DNA fragment was generated containing $36 \mathrm{bp}$ of the remaining intron sequence of eas $G$ gene that was incorporated into the reverse primer followed by $450 \mathrm{bp}$ of the eas $A$ coding sequence in reverse-complement orientation. After PCR, both fragments were pooled and digested with BsrGI (BsrGI recognition sites were built into primers RNAi-2 and RNAi-3) and ligated to yield a $947 \mathrm{bp}$ fragment. The fragment was then digested with Xhol and Notl (recognition sites for which were built into the 5'-ends of primers RNAi-1 and RNAi-4, respectively), ligated into Xhol and Notl digested pCB1004, and electroporated into Escherichia coli cells. The resulting transformants were selected on chloramphenicol. The plasmid vector, pEASAi (Fig. 2A) was isolated, and integrity of the easA-RNAi construct was checked by sequencing into the insert from flanking vector regions. Sequencing of the coding regions of eas $A$ was greatly inhibited by secondary structure formation, so digestion with different restriction enzymes and analysis of the restricted fragments was performed to confirm that the desired construct had been obtained. Transcription of the easA-RNAi fragment was driven by a strong toxA promoter which was amplified from Pyrenophora tritici-repentis DNA with primers toxA-F and toxA-R and cloned as a Kpnl-Xhol fragment into pCB1004, prior to cloning the easA-RNAi segment into the plasmid. The trpC terminator was amplified from Aspergillus nidulans $\operatorname{trp} C$ gene using primers trpC-F and trpC-R and inserted it at a unique Sacl site in the plasmid. 


\section{Generation of easA overexpression construct:}

In order to overexpress the eas $A$ gene, eas $A$ coding sequence was fused to the promoter of gigA from Neotyphodium sp. Lp1 (Johnson et al., 2003), which is the most highly expressed endophyte gene during symbiosis. Using primers easAO-1 and easAO-2, the eas $A$ coding sequence was amplified as a 1551 bp DNA fragment containing Notl and BsrGl sites at the 5' and 3' end respectively. The promoter of Nc25 was amplified as a 576-bp Xhol-BsrG/ fragment with primers Nc25-F and Nc25-R. The PCR products were then purified, pooled, digested with BsrGI, and ligated. The resulting $2127 \mathrm{bp}$ fragment was then digested with $\mathrm{Xhol}$ and Notl and cloned into Xhol and Notl digested pCB1004 vector and electroporated into E. colicells. The plasmid vector, pEASAo (Fig. 2B) was isolated from transformants and integrity of the construct was checked by sequencing.

\section{Fungal transformation and plant infection.}

Protoplasts were prepared and transformed based on methods described by Panaccione et al. (2001). Transformants were selected for on a medium containing 200 $\mu \mathrm{gL}^{-1}$ hygromycin B (Calbiochem, San Diego, CA). After 5 weeks, viable hygromycinresistant fungal colonies were transferred onto PDA to induce sporulation. The transformants were then screened for integration of the desired plasmid construct by PCR by primers hyg-F and hyg-R, which target the hygromycin resistance gene of the plasmid. Positive transformants were purified to nuclear homogeneity by culturing them from single spores. Perennial ryegrass cv. Rosalin were inoculated with single-spored genetically modified endophytes according to methods described by Panaccione et al. (2001). 


\section{Analysis of ergot alkaloids.}

Ergot alkaloids were extracted from $50 \mathrm{mg}$ of dried powdered plant material as described previously by Panaccione et al. (2006). Ergot alkaloids were quantified from $20 \mu \mathrm{L}$ of the supernatant by high-pressure liquid chromatography (HPLC) over a $\mathrm{C}_{18}$ column (Prodigy 5- $\mu \mathrm{m}$ ODS3 [150 mm by $4.6 \mathrm{~mm}$ ]; Phenomenex, Torrance, CA) with acetonitrile-ammonium acetate gradients. Chanoclavine was detected by a fluorescent detector set at excitation and emission wavelengths of $272 \mathrm{~nm}$ and $372 \mathrm{~nm}$, respectively. All other ergot alkaloids were detected by excitation at $310 \mathrm{~nm}$ and emission at $410 \mathrm{~nm}$ (Panaccione et al., 2006). Quantification of ergot alkaloids was based on comparison of peak areas to those of internal standard ergotamine-tartrate (Sigma, St, Louis, MO) that was added to the plant material along with the extraction buffer. Data was analyzed by ANOVA using the general linear models procedure of SAS (Cary, NC).

\section{RESULTS}

Tissue specific accumulation of ergot alkaloids.

Ergot alkaloids were detected and quantified in different perennial ryegrass tissues colonized with wild-type Neotyphodium sp. Lp1. Concentrations of total alkaloids that include pathway intermediate chanoclavine, shunt products 6,7-secolysergine and setoclavine, and end products ergine and ergovaline differed significantly in pseudostem, center leaf blade, outer leaf blade, flag leaf, inflorescence, and dough stage seeds $(P=0.0001)$ (Fig. 3$)$. Dough stage seeds accumulated the highest conentrations of total alkaloids followed by pseudostems. Total alkaloids were of similar 
concentrations in the outer leaf blade, center leaf blade and inflorescence but differed significantly from dough stage, pseudostem, and flag leaf. Flag leaf tissue had very low total alkaloid concentrations with only detectable 6,7-secolysergine and ergine alkaloids. Concentrations of individual alkaloids varied significantly within and among tissues representing different developmental stages of the plant $(P<0.05)$ (Fig. 4). Within individual tissues, dough stage seeds and pseudostems accumulate high amounts of pathway end product ergovaline when compared to all other alkaloids. Conversely, inflorescence tissue accumulates higher chanoclavine levels and lower amounts of other alkaloids. When concentrations of different alkaloids were compared among tissues, the pathway intermediate chanoclavine accumulated in significantly higher concentrations in pseudostems, inflorescence, and dough stage $(P<0.05)$ than in other tissues. Shunt product 6,7-secolysergine was detected in higher concentrations in dough stage seeds $(P<0.05)$, which also accumulated very high concentrations of pathway end products. Setoclavine was rarely detected in any of the host tissues.

Transcript accumulation data were also looked at in terms of expression of individual genes in all the different tissues used in the study. This work was performed by Dr. Simona Florea in the laboratory of Dr. Christopher Schardl at the University of Kentucky and is described in Appendix 1.

\section{Ergot alkaloid analysis of the plants colonized by genetically modified endophyte} strains.

Alteration of mRNA levels of easA employing RNAi and overexpression strategies changed the flow of metabolites through the ergot alkaloid pathway of Neotyphodium sp. Lp1. When compared to the wild-type, plants colonized by two of the three different 
strains of easA RNAi fungi and easA overexpressing Neotyphodium sp. Lp1 differed significantly in accumulation of ergot alkaloids (Fig. 5-8). Each strain represented an independent, random integration event.

Alteration of ergot alkaloid profiles in pseudostem and outer leaf blades of plants infected by easA RNAi strains:

Plants colonized by Neotyphodium sp. Lp1 strain in which easA has been knocked down by RNAi showed significant differences in the accumulation of an ergot alkaloid pathway intermediate, a by-product, and an end product. Pseudostems colonized by easA-RNAi-1 fungus had significantly higher accumulation of chanoclavine $(P=$ 0.0050), an early pathway intermediate, and 6,7-secolysergine, a pathway shunt product $(P=0.0075)$, and lower accumulation of ergovaline $(P=0.013)$, the end product of the pathway, than did pseudostems colonized with the wild type (Fig. 5A). Outer leaf blades from the same plants also accumulated significantly high concentrations of $6,7-$ secolysergine $(P=0.0148)$ and less ergovaline $(P=0.0008)($ Fig. $6 \mathrm{~A})$, when compared to the wild type. No detectable chanoclavine was found in the outer leaf blades. Similar results were measured in pseudostems and leaf blades colonized by strain easA-RNAi2 strain (Fig. 5B and 6B). In contrast, accumulation of ergot alkaloids in plants infected with strain easA-RNAi-3 did not differ significantly from that of wild type-infected plants (Fig. 5C and 6C).

In collaboration with Drs. Florea and Schardl (University of Kentucky), transcript accumulation of eas $A$ was also looked at in the same samples of pseudostem that were used for alkaloid analysis (Appendix 1). 
Alteration of ergot alkaloid profiles in pseudostem and outer leaf blades of plants infected by easA overexpression strains:

Pseudostems colonized by eas $A$-overexpression-1 strain had significantly more ergovaline, the pathway end product, $(P=0.014)$ and no significant difference in accumulation of intermediate chanoclavine and by-product 6,7-secolysergine (Fig. 7A), when compared to the wild type. Outer leaf blades from the same plants also accumulated significantly more ergovaline than plants infected with the wild type $(P=$ 0.018) (Fig. 8A). No difference in the levels of 6,7-secolysergine were detected in leaf blades when compared to the wild type (Fig. 8A). Chanoclavine was not detected in the outer leaf blades. Similar alkaloid concentrations and distribution was detected in pseudostems and leaf blades colonized by the easA-overexpression-2 strain (Fig. 7B and $8 \mathrm{~B})$. In contrast, easA-overexpression-3 strain did not show any significant difference in the accumulation of ergot alkaloids when compared to wild type (Fig. 7C and $8 \mathrm{C})$.

In collaboration with Drs. Florea and Schardl (University of Kentucky), transcript accumulation of eas $A$ was also looked at in the same samples of pseudostem that were used for alkaloid analysis (Appendix 1).

\section{DISCUSSION}

Results from this study have provided new insights into how different ergot alkaloid profiles can result from differing efficiency in turning over intermediates in the ergot alkaloid pathway of Neotyphodium sp. Lp1 that is symbiotic with perennial ryegrass. 
Results from analysis of different tissues of perennial ryegrass infected with the wild type showed that the ergot alkaloid pathway efficiency varies at tissue level. mRNA from various ergot alkaloid pathway genes was present in all tissue type (Appendix 1) but variation in levels of individual genes may account in part to the varied levels of alkaloids detected in these tissues. Through RNAi and over-expression transformant analysis, I have established that alteration of easA mRNA can change the efficiency of the ergot alkaloid pathway in Neotyphodium sp. Lp1. When compared to wild type, transformants with RNAi-mediated knock down of easA had higher accumulation of pathway intermediate chanoclavine and shunt product 6,7-secolysergine and lower accumulation of pathway end product ergovaline. Furthermore, over-expression of eas $A$ resulted in a very high accumulation of pathway end product ergovaline compared to the wild type, but there was no significant difference in the accumulation of intermediate chanoclavine and shunt product 6,7-secolysergine alkaloid.

Results from analyses of ergot alkaloids in various tissues of perennial ryegrass showed that ergot alkaloid profiles differed by tissue, with some tissues, like dough stage of seeds, being more efficient in turning over intermediates and other stages, like inflorescences, being highly inefficient. Analyses of mRNA from several ergot alkaloid pathway genes indicate that ergot alkaloid pathway efficiency is influenced by the accumulation of mRNA for different ergot alkaloid pathway enzymes (Appendix 1). All the ergot pathway genes tested in the study were ubiquitously expressed in all the tissues, but there was differential expression of these genes in different tissues which may contribute to the difference in ergot alkaloid accumulation (Appendix 1). This is exemplified by the high abundance of IpsA mRNA in pseudostems and center leaf blade 
and $c l o A$ in dough stage seeds which may contribute to the higher accumulation of pathway end product in these tissues (Appendix 1).

In addition to variation in profiles, different tissues varied in accumulation of total ergot alkaloids. Pseudostems and dough stage seeds had higher accumulations of alkaloids, whereas flag leaf had very low levels of alkaloids which can be due to the low fungal biomass in flag leaf and higher fungal biomass in pseudostem and dough stage seeds (S. Florea and C.L. Schardl, pers.com). In addition to mRNA abundance, relative fungal colonization of different tissues, substrate availability in different tissues, and translocation of alkaloids from their site of synthesis also could affect the levels of alkaloids in different tissues.

Neotyphodium sp. Lp1 is a systemic and seed-transmitted obligate symbiont of perennial ryegrass that is completely reliant on the host plant for its existence. Since the fungus is dispersed only via infected seeds (Schardl, 1996), it has to defend the host resources, thereby enhancing its frequency of transmission into the next generation. Therefore, an inefficient pathway that results in the varied profiles of alkaloids in different tissues would be selected for if intermediates and end products provided different benefits to the host plant. Recent evidence from studies with endophytes in which the ergot alkaloid pathway was truncated at different steps support the hypothesis that inefficiency in the ergot alkaloid pathway is beneficial (Panaccione, 2005; Panaccione et al., 2006; Potter et al., 2008). Moreover, since different stresses are likely to be encountered by different tissues, variation of pathway efficiency by tissue could be advantageous to the symbiotum. The plant's basal meristem and seeds are most vital for the fungus to defend, which may account for the high amounts of total 
detectable alkaloids in seeds and pseudostems, which protect the basal meristematic regions. The presence of alkaloids in leaves is a possible way of the endophyte to protect its host's resources from grazing animals.

Recent evidence has shown that knock out of eas $A$ in $A$. fumigatus, results in the accumulation of high concentrations of chanoclavine and lesser amounts of chanoclavine aldehyde (Coyle et al., 2010). So the product of eas $A$ is required for the formation of more complex tetracyclic ergot alkaloids, such as agroclavine, from the simple tricyclic alkaloids such as chanoclavine in Neotyphodium sp. Lp1 (Cheng et al., 2010; Coyle et al., 2010). Analyses of different tissues of perennial ryegrass inhabited by Neotyphodium sp. Lp1 support previous findings that only trace quantities of intermediates such as agroclavine, elymoclavine, lysergic acid are detected between intermediate chanoclavine and pathway end product ergovaline (Panaccione et al., 2003; Panaccione, 2005). This suggests that once agroclavine, the first tetracylic intermediate, is formed, the pathway flows very efficiently and results in the production of ergovaline. Although alkaloid and mRNA results from RNAi-mediated knock down of eas $A$ suggest that eas $A$ strongly affects the efficiency in the flow of intermediates down the ergot alkaloid pathway after the formation of chanoclavine, alkaloid and mRNA data from eas $A$ overexpression analyses indicated no change in the levels of chanoclavine. When eas $A$ is over expressed all the intermediate chanoclavine should be converted into further downstream alkaloids. The fact that we do not see any change in levels of chanoclavine of overexpression strains in comparison to the wild-type indicates that when chanoclavine levels fall below the threshold value it probably results in up 
regulation of the genes upstream to eas $A$. This upregulation could have further led to increased chanoclavine accumulation.

Endophytes, by means of their ergot alkaloid production, impart toxic properties to their host plants, making them less desirable as forage crops. Toxicity can be possibly ameliorated by using endophytes with altered ergot alkaloid profiles. Symbiota with genetically altered ergot alkaloid profiles generated by this study may be used to differentiate the role of individual ergot alkaloids in animal toxicity and in other endophyte associated traits. Since the endophyte is transmissible only via seeds the generation and incorporation of agronomically desired traits conferred by genetically modified endophytes may provide a viable strategy in controlling animal toxicity.

\section{ACKNOWLEDGMENTS}

This work was supported by grant number 2008-35318-04549 from the United States Department of Agriculture, National Institute of Food and Agriculture, and published with permission of the West Virginia Agriculture and Forestry Experiment Station as scientific article number (supplied upon acceptance). I thank Dr. Florea (Dr. Schardl's lab, University of Kentucky) for performing the real time PCR analysis and Dr. Schardl's laboratory (University of Kentucky) for plant infections. 


\section{REFERENCES.}

Bush, L.P., Wilkinson, H.H., Schardl, C.L. 1997. Bioprotective alkaloids of grass-fungal endophyte symbioses. Plant Physiol 114, 1-7.

Clay, K., Schardl, C. 2002. Evolutionary origins and ecological consequences of endophyte symbiosis with grasses. Am Nat 160 Suppl 4, S99-S127.

Filipov, N.M., Thompson, F.N., Hill, N.S., Dawe, D.L., Stuedemann, J.A., Price, J.C., Smith, C.K. 1998. Vaccination against ergot alkaloids and the effect of endophyteinfected fescue seed-based diets on rabbits. J Anim Sci 76, 2456-2463.

Gadberry, M.S., Denard, T.M., Spiers, D.E., Piper, E.L. 2003. Effects of feeding ergovaline on lamb performance in a heat stress environment. J Anim Sci 81, 15381545.

Ganetsky, M., and D. E. Brush. 2005. Serotonin Syndrome- What have we learned? Pediatric Emergency Medicine 6:103-108.

Goetz, C. G., and N. J. Diederich. 1992. Dopaminergic agonists in the treatment of Parkinson's disease. Neurol Clin 10:527-540.

Hill, N.S., Thompson, F.N., Dawe, D.L., Stuedemann, J.A. 1994. Antibody binding of circulating ergot alkaloids in cattle grazing tall fescue. Am J Vet Res 55, 419-424.

Johnson, L.J., Johnson, R.D., Schardl, C.L., Panaccione, D.G. 2003. Identification of differentially expressed genes in the mutualistic association of tall fescue grass with Neotyphodium coenophialum. Physiol Mol Plant Pathol 63, 305-317.

Malinowski, D., Belesky, D. 2006. Ecological importance of Neotyphodium spp. grass endophytes in agroecosystems. Grassland Science 52, 1-14. 
Panaccione, D. 2010. Ergot Alkaloids. The Mycota 10:195-214. In: Hofrichter (ed), Industrial Application, $2^{\text {nd }}$ edn. Springer-Verlag, Berlin-Heidelburg.

Panaccione, D.G. 2005. Origins and significance of ergot alkaloid diversity in fungi. FEMS Microbiol Lett 251, 9-17.

Panaccione, D.G., Cipoletti, J.R., Sedlock, A.B., Blemings, K.P., Schardl, C.L., Machado, C., Seidel, G.E. 2006. Effects of ergot alkaloids on food preference and satiety in rabbits, as assessed with gene-knockout endophytes in perennial ryegrass (Lolium perenne). J Agric Food Chem 54, 4582-4587.

Panaccione, D.G., Coyle, C.M. 2005. Abundant respirable ergot alkaloids from the common airborne fungus Aspergillus fumigatus. Appl Environ Microbiol 71, 3106-3111.

Panaccione, D.G., Schardl, C.L., and Coyle, C.M. 2006. Pathways to diverse ergot alkaloid profiles in fungi. Recent Advances in Phytochemistry. 40:23-52.

Panaccione, D.G., Tapper, B.A., Lane, G.A., Davies, E., Fraser, K. 2003. Biochemical outcome of blocking the ergot alkaloid pathway of a grass endophyte. J Agric Food Chem 51, 6429-6437.

Pertz, H., and E. Eich. 1999. Ergot alkaloids and their derivatives as ligands for serotoninergic, dopaminergic, and adrenergic receptors, p. 411-440. In V. Kren and L. Cvak (ed.), Ergot: The Genus Claviceps. Harwood Academic Publishers, The Netherlands.

Schardl, C.L. 1996. Epichloe Species: fungal symbionts of grasses. Annu Rev Phytopathol 34, 109-130.

Schardl, C., Phillips, T. 1997. Protective Grass Endophytes: Where are they from and where are they going? Plant Disease 81, 430-438. 
Schardl, C.L., Leuchtmann, A., Tsai, H.F., Collett, M.A., Watt, D.M., Scott, D.B. 1994. Origin of a fungal symbiont of perennial ryegrass by interspecific hybridization of a mutualist with the ryegrass choke pathogen, Epichloe typhina. Genetics 136, 13071317.

Schardl, C.L., Panaccione, D.G., Tudzynski, P. 2006. Ergot alkaloids--biology and molecular biology. Alkaloids Chem Biol 63, 45-86. 


\section{FIGURE LEGENDS}

Figure 1: Condensed version of the ergot alkaloid biosynthetic pathway of Neotyphodium sp. Lp1. Multiple arrows indicate omitted intermediates.

Figure 2: Schematic representation of easA RNAi and overexpression constructs. (A) Map of the RNAi plasmid construct containing the easA sequence under the control of the toxA promoter from Pyrenophora tritici-repentis and the trpC terminator from $A$. nidulans. The elements of the plasmid are represented by open and shaded boxes which are, respectively, the coding regions of easA, artificially engineered intron (sequence indicated by lowercase letters) between the complementary eas $A$ coding sequences (represented by uppercase letters). The underlined sequence indicates the $B s r G /$ recognition sequence introduced for cloning. (B) Map of the easA overexpression plasmid construct containing the eas $A$ sequence driven by the gigA promoter derived from Neotyphodium sp. Lp1.

Figure 3: Total ergot alkaloid levels in pseudostem, center leaf, outer leaf, flag leaf, inflorescence and dough stage seeds of the perennial ryegrass infected with wild-type Neotyphodium sp. Lp1 ( $\mathrm{n}=3)$.

Figure 4: Accumulation of indicated ergot alkaloids in pseudostem, center leaf, outer leaf, flag leaf, inflorescence and dough stage seeds of the perennial ryegrass plant infected with wild-type Neotyphodium sp. Lp1 $(n=3)$. 
Figure 5: Levels of indicated ergot alkaloids in pseudostem tissue of perennial ryegrass infected with (A) easA RNAi-1, (B) easA RNAi-2 and (C) easA RNAi-3 transformant Neotyphodium sp. Lp1 strains. Asterisks represent significant differences $(P<0.05)$ between transformant and wild type $(n=3)$.

Figure 6: Levels of indicated ergot alkaloids in leaf tissue of perennial ryegrass infected with (A) easA RNAi-1, (B) easA RNAi-2 and (C) easA RNAi-3 transformant Neotyphodium sp. Lp1 strains. Asterisks represent significant differences $(P<0.05)$ between transformant and wild type.

Figure 7: Levels of indicated ergot alkaloids in pseudostem tissue of perennial ryegrass infected with (A) easA overexpression -1, (B) easA overexpression -2 and (C) easA overexpression -3 transformant Neotyphodium sp. Lp1 strains. Asterisks represent significant differences $(P<0.05)$ between transformant and wild type $(n=3)$.

Figure 8: Levels of indicated ergot alkaloids in leaf tissue of perennial ryegrass infected with (A) easA overexpression -1, (B) easA overexpression-2 and (C) easA overexpression-3 transformant Neotyphodium sp. Lp1 strains. Asterisks represent significant differences $(P<0.05)$ between transformant and wild type $(n=3)$. 
Table 1: Primers used in this study. $F$, forward primer; $R$, reverse primer.

\begin{tabular}{|c|c|}
\hline $\begin{array}{l}\text { Primer } \\
\text { name }\end{array}$ & Sequence $5^{\prime}-3^{\prime}$ \\
\hline $\begin{array}{l}\text { RNAi-1F } \\
\text { RNAi-2R }\end{array}$ & $\begin{array}{l}\text { CACCTCGAGGCTGTGTTTGCGCATCATTATGTC } \\
\text { CACTGTACAAATAGTCATACCCGATGTATGAGTTGATCTCATC } \\
\text { G }\end{array}$ \\
\hline $\begin{array}{l}\text { RNAi-3F } \\
\text { RNAi-4R }\end{array}$ & $\begin{array}{l}\text { CACTGTACAGTTAGAACAAAGAATGAAATTAACGTATAACGAT } \\
\text { AGCCGATGTATGAGTTGATCTCATCG } \\
\text { GATCTATGCGGCCGCGGCTGTGTTTGCGCATCATTATGTC }\end{array}$ \\
\hline $\begin{array}{l}\text { toxA-F } \\
\text { toxA-R }\end{array}$ & $\begin{array}{l}\text { TAGTGGGGTACCGGAATCCATGGAGGAGT } \\
\text { GATAGAACTCGAGCCTATATTCATTCATT }\end{array}$ \\
\hline $\begin{array}{l}\operatorname{trpC}-\mathrm{F} \\
\operatorname{trpC}-\mathrm{R}\end{array}$ & $\begin{array}{l}\text { TGACGTGAGCTCTAGTGATTTAATAGCTCCAT } \\
\text { GATAGAGAGCTCCATTCACTAGGCAACCATGGTTAC }\end{array}$ \\
\hline $\begin{array}{l}\text { easAO-1-F } \\
\text { easAO-1-R }\end{array}$ & $\begin{array}{l}\text { CACTGTACAGCTGTGTTTGCGCATCATTATGTC } \\
\text { GACGCGGCCGCCCTTGGGTTATCCTACCGACTACA }\end{array}$ \\
\hline $\begin{array}{l}\text { Nc25-F } \\
\text { Nc25-R }\end{array}$ & $\begin{array}{l}\text { GTACTCGAGCTACTGCGTATAGAGTAGTGAGTA } \\
\text { CACTGTACAGGTGAACGTTTTTGACTGTTG }\end{array}$ \\
\hline $\begin{array}{l}\text { hyg-F } \\
\text { hyg-R }\end{array}$ & $\begin{array}{l}\text { CCGTGGAGGTAATAATTGA } \\
\text { CGAAGAACGTTTTCCAATGA }\end{array}$ \\
\hline
\end{tabular}


FIGURE 1.

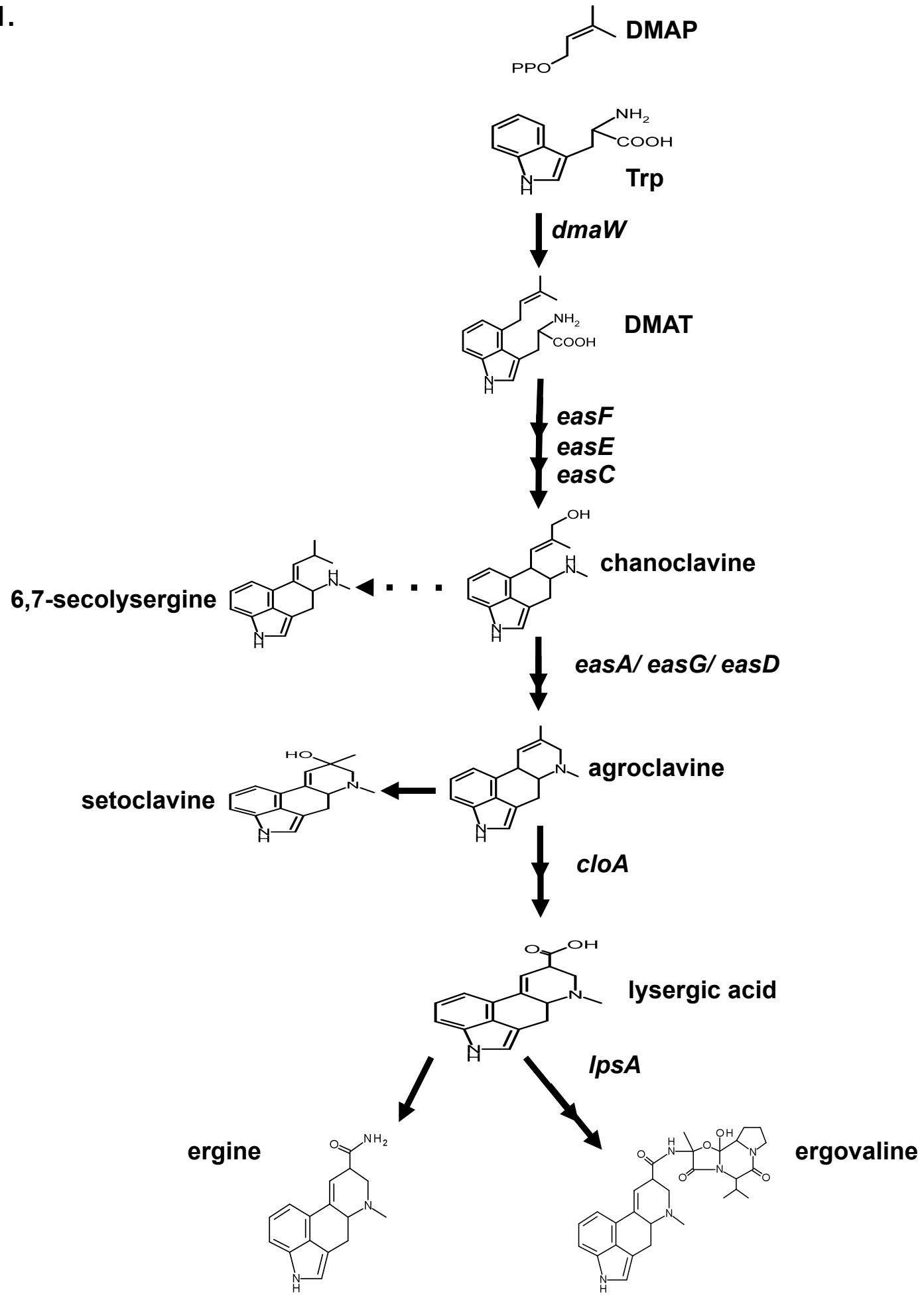




\section{FIGURE 2.}

A

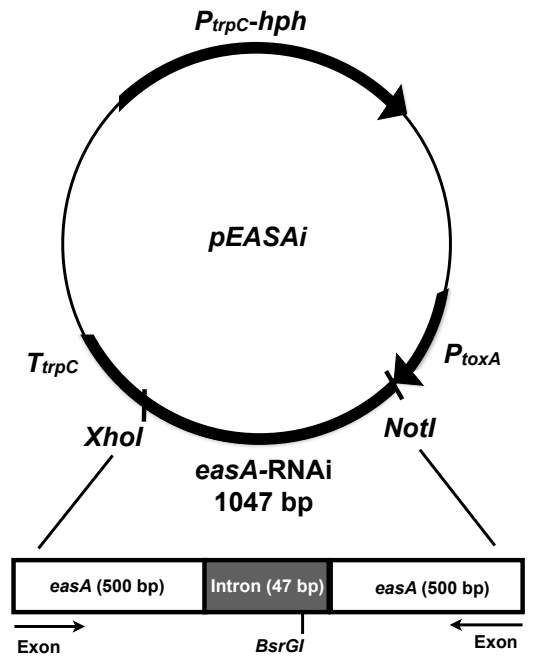

...CATACATCGGgtatgactatttgtacagttagaacaaagaatgaaattaacgtataacgatagCCGATGTATG...

B

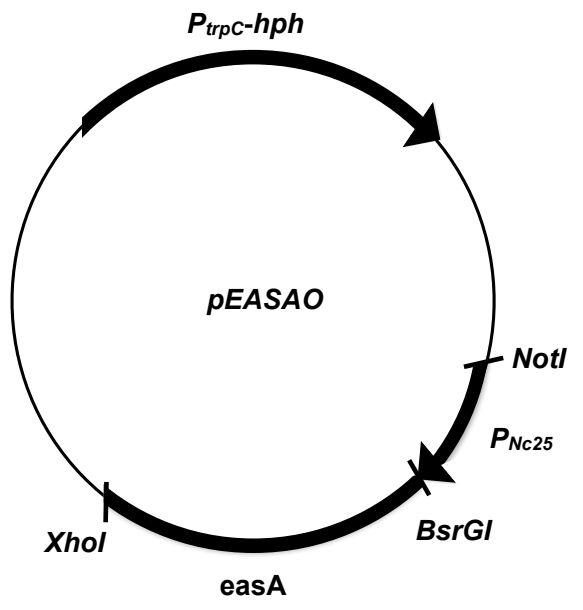


FIGURE 3.

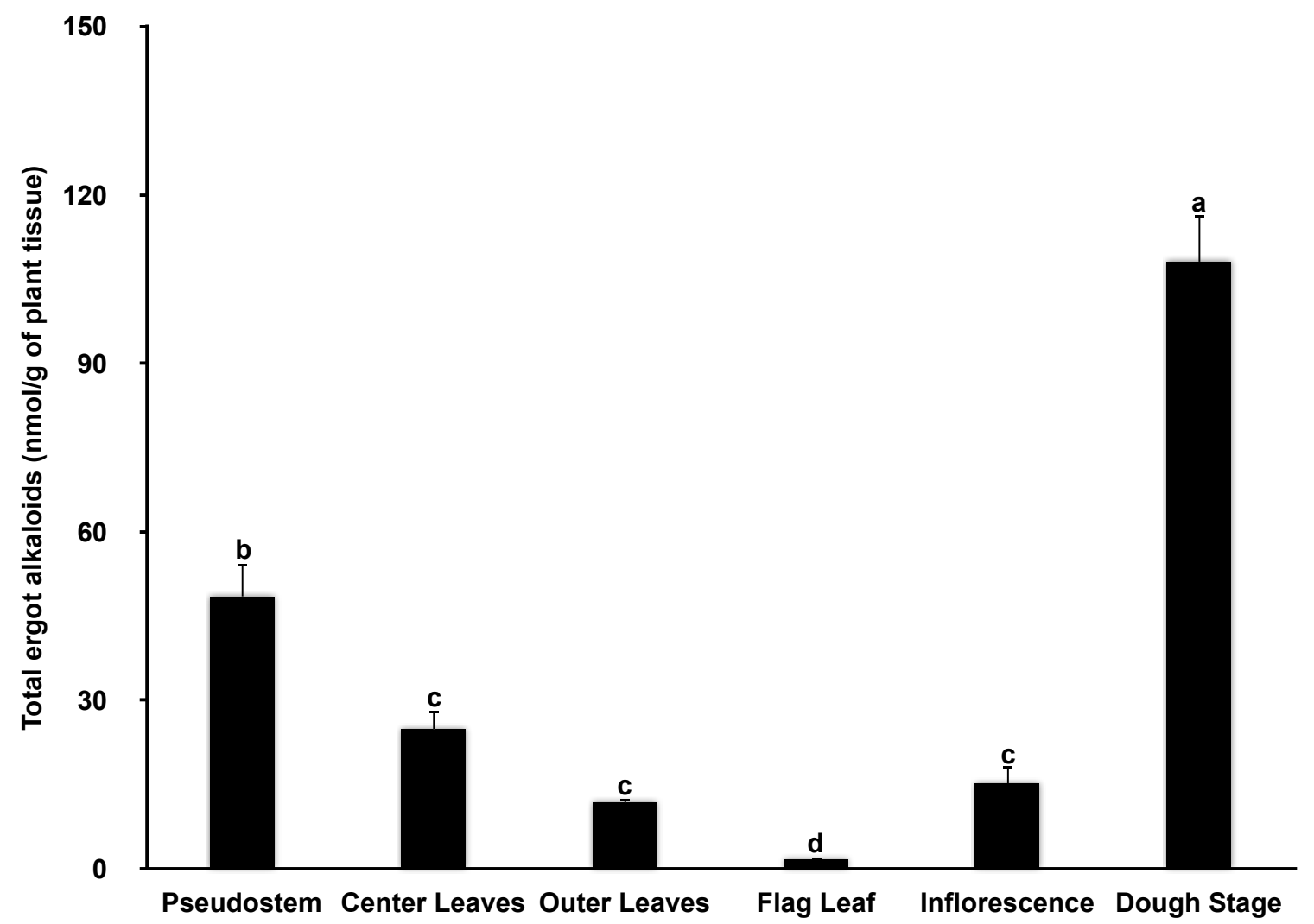




\section{FIGURE 4.}

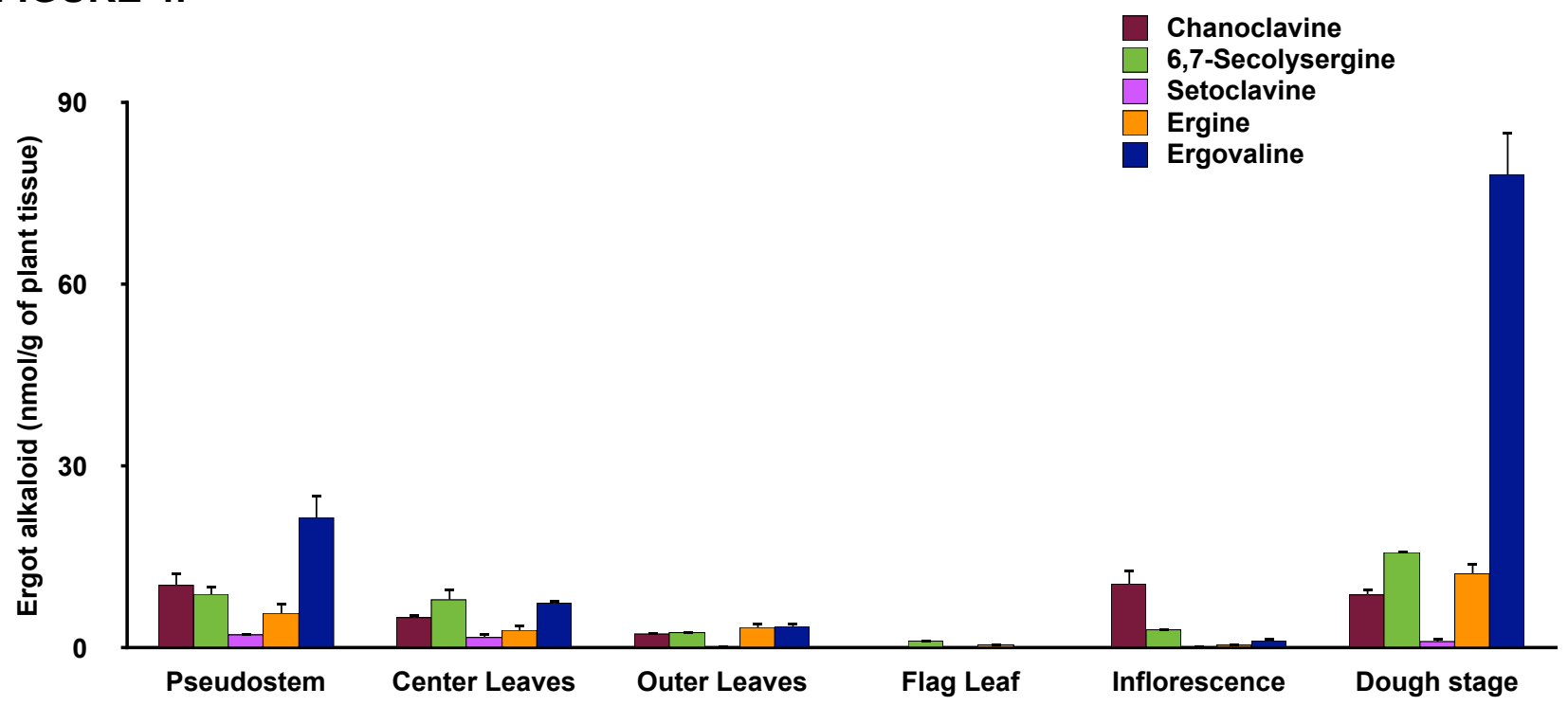




\section{FIGURE 5.}

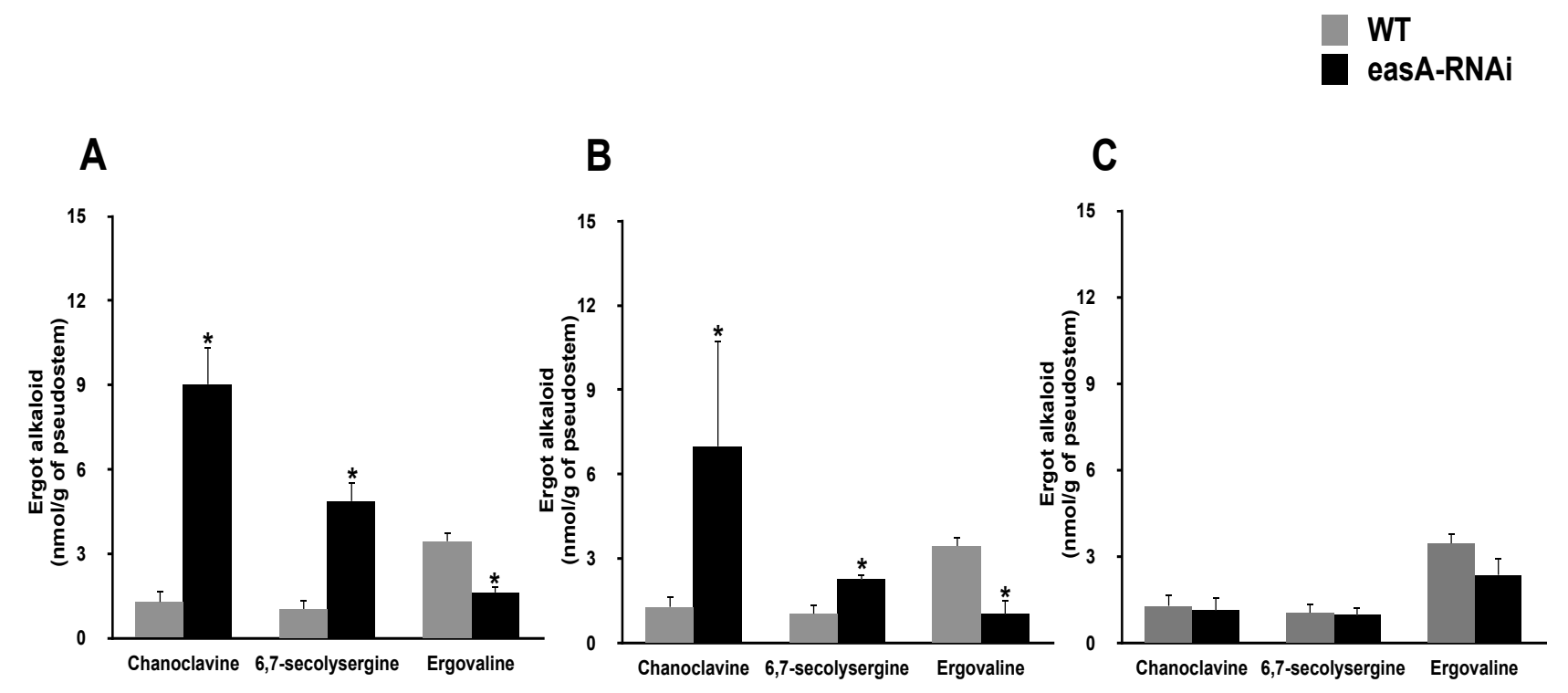




\section{FIGURE 6.}

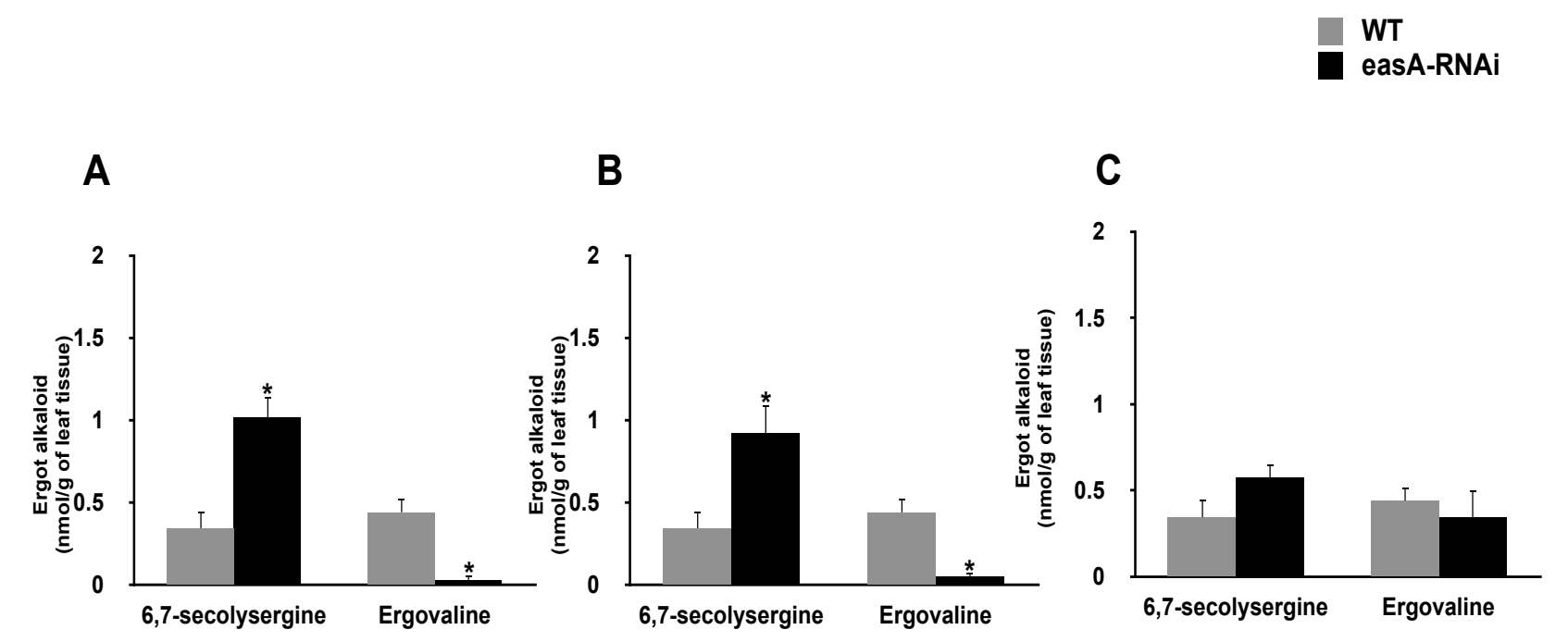




\section{FIGURE 7.}

WT

a easA-Overexpression
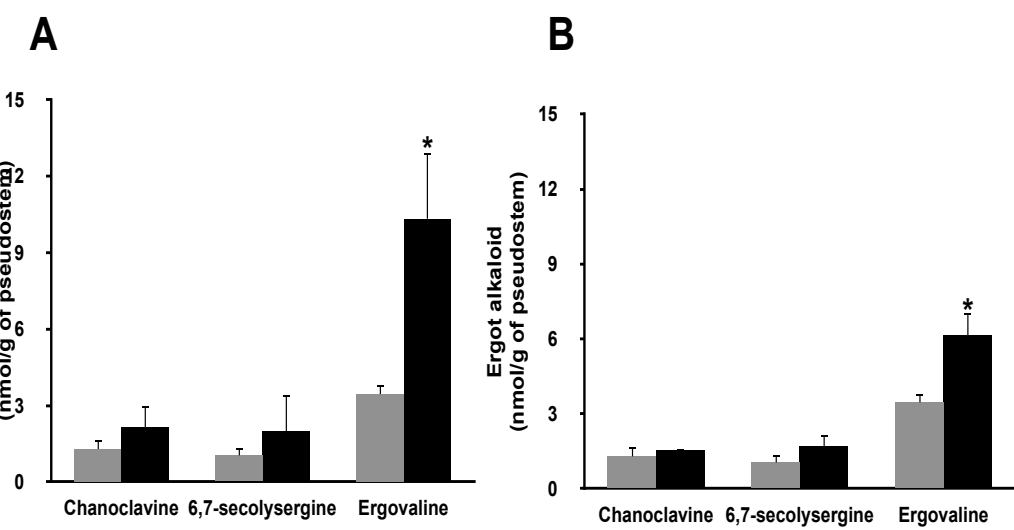

C

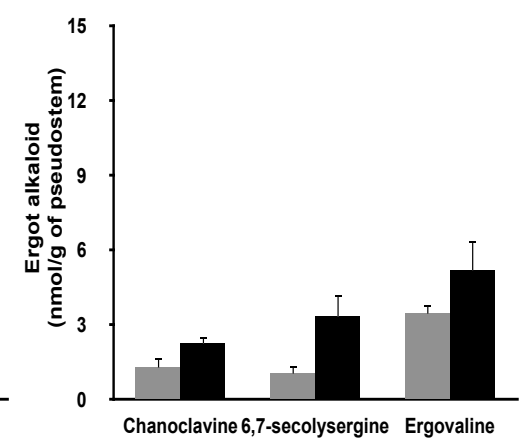




\section{FIGURE 8.}

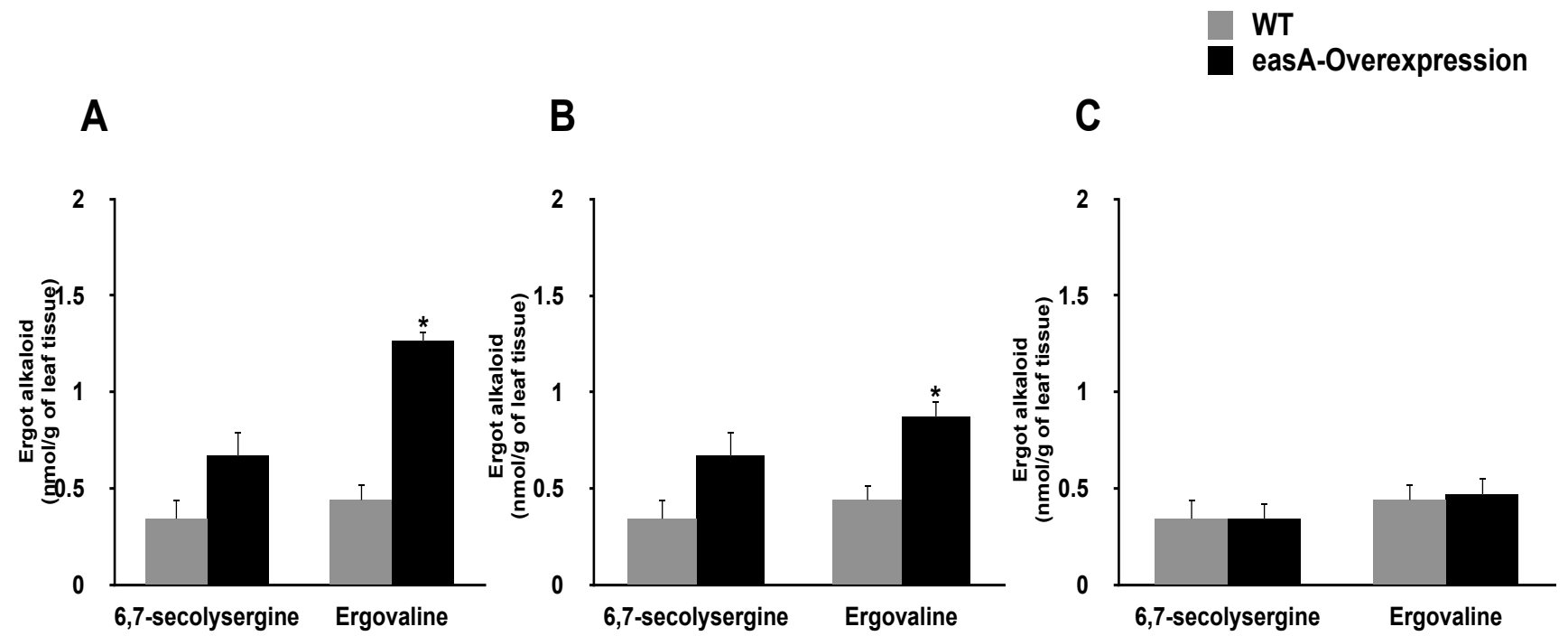


APPENDIX-1 
Real-time PCR analysis of grass symbiota containing wild-type and transformed

\section{Neotyphodium Iolii $\times$ Epichloë typhina isolate \\ Lp1 (Neotyphodium sp. Lp1).}

Original data from research by Dr. Simona Florea, University of Kentucky

Summarized by Prashanthi Mulinti 


\section{INTRODUCTION}

Dr. Florea performed real-time PCR analysis on the same pseudostem tissues that were analyzed for ergot alkaloids in Chapter 2, to check the accumulation of mRNA from certain ergot alkaloid cluster genes. I am summarizing Dr. Florea's findings here, because comparison of alkaloid and mRNA data will provide important information about factors affecting flow of intermediates through the ergot alkaloid pathway.

\section{MATERIALS AND METHODS}

\section{Tissue collection and RNA isolation}

Pseudostems were collected from plants inoculated with Neotyphodium sp. Lp1 and rapidly frozen in liquid nitrogen. Total RNA was isolated from $100 \mathrm{mg}$ of each sample by application of the RNeasy Plant Mini kit (Qiagen, Valencia, CA, USA) according to manufacturer's instructions. The RNA integrity was determined by agarose gel electrophoresis.

\section{DNase treatment and Reverse transcription}

The total RNA was treated for removal of contaminating DNA with DNA-free kit (Ambion, Austin, TX) and quantified by Qubit fluorometer (Invitrogen, USA) following the recommendations of Quant-iT RNA Assay Kit. The cDNA was synthesized from $1 \mu \mathrm{g}$ RNA by application of the High-Capacity cDNA Reverse Transcription Kit (Applied Biosystems) according to manufacturer's instructions.

\section{Real-Time quantitative PCR (RT-qPCR)}


The RT-qPCR assays were performed in 7900 HT Fast Real-Time PCR System (Applied Biosystems) employing SYBR green detection. The RT-qPCRs were conducted in 96-microwell plates, where each sample-gene combination was loaded in triplicate. The reactions contained $5 \mu \mathrm{L}$ of cDNA, $10 \mu \mathrm{L}$ SYBR mix and $0.4 \mu \mathrm{M}$ of each primer in a final reaction volume of $20 \mu \mathrm{L}$. The primers for the target genes (dmaW, eas $A, \operatorname{clo} A, \operatorname{Ips} A$, eas $C$, and eas $D$ ) and the reference genes (tefA and $E F 1-\alpha$ ) were generated by IDT (Coraville, IA, USA) and are listed in Table 1. The relative metabolically active fungal biomass in different tissues was estimated by measuring the mRNA level of fungal gene tefA (encoding translation elongation factor 1- $\alpha$ ) with the plant translation elongation factor 1- $\alpha(E F 1-\alpha)$ mRNA as reference. Expression of all tested genes was calculated with the relative comparative $\mathrm{Ct}$ method $(\Delta \Delta \mathrm{Ct}=$ normalized $\mathrm{Ct}$ as $\Delta \mathrm{Ct}-$ calibrator, where $\Delta \mathrm{Ct}=\mathrm{Ct}$ of target gene $-\mathrm{Ct}$ of tefA, and calibrator $=$ median of $\Delta \mathrm{Ct})$, using tefA as the reference gene for normalization. For each gene, the relative level of gene expression was then converted into fold-difference relative to the calibrator as $2^{-\Delta \Delta C t}$ (Livak and Schmittgen 2001).

\section{RESULTS AND DISCUSSION}

Real-time data indicated that although there is ubiquitous expression of all pathway genes tested in all the tissues, significant differences in mRNA abundance of different pathway genes was detected among different tissues $(P<0.05)$ (Fig. 1). The high mRNA abundance of IpsA, which is required for the formation of pathway end product ergovaline (Panaccione et al., 2001), in pseudostem and center leaf is consistent with the higher accumulation of ergovaline in these tissues. The high mRNA levels of cloA, 
which catalyzes the formation of lysergic acid from elymoclavine (Haarmann et al., 2006), in dough stage seeds is consistent with higher accumulation of end products of the pathway. Within an individual tissue there was no significant difference in the abundance of mRNA of different pathway genes indicating that factors other than mRNA abundance contribute to the accumulation of alkaloids in different tissues.

RT-PCR analysis also was performed on pseudostems from plants infected with easA RNAi and overexpression transformants, to measure accumulation of eas $A$ mRNA. Quantities of transcripts of dmaW also were determined, since dmaW controls the first determinant step of the ergot pathway (Wang et al., 2004). Similarly, mRNA of tef $A$, which encodes translation elongation factor $1-\alpha$, was measured to estimate the relative amount of metabolically active fungal biomass among the tissues. RT-PCR analysis was performed on plants representing three different easA RNAi Neotyphodium sp. Lp1 transformants (easA-RNAi-1, easA-RNAi-2 and easA-RNAi-3) and three easA overexpression Neotyphodium sp. Lp1 strains (easA-overexpression-1, easA-overexpression-2 and easA-overexpression-3). The data are depicted in Figures 2 and 3 respectively.

Data from RT-PCR analysis of eas $A$ gene in RNAi 1 and 2 transformants indicate that the lower levels of mRNA of easA resulted in lower accumulation of pathway end product ergovaline and higher accumulation of chanoclavine and shunt product $6,7-$ secolysergine (Fig. 2A and B). In overexpression transformants 1 and 2 , the high quantities of easA mRNA are consistent with the observed differences in ergot alkaloid accumulation in these transformants (Fig. $3 \mathrm{~A}$ and $\mathrm{B}$ ). The concentrations of tefA mRNA indicated that there was no significant difference in fungal biomass between the 
transformants and wild type (Fig 2 and 3). Data from easA-RNAi-3 and easA-

overexpression-3 strains did not show any significant difference in the expression of the ergot pathway genes when compared to wild type, which supports the lack of difference observed in the alkaloid data (Fig. 2C and 3C).

\section{CONCLUSION}

Collectively, results from this study demonstrate that the ergot pathway inefficiency which results in differential accumulation of ergot alkaloids in different tissues of the grass plant is strictly regulated and is atleast in part under the control of tightly regulated expression of ergot pathway genes. RT-PCR analysis of easA gene indicates that the observed variation in the ergot alkaloid profile of RNAi and overexpression transformants coincides with the change in mRNA abundance of easA gene. 


\section{REFERENCES}

Haarmann, T., Ortel, I., Tudzynski, P., Keller, U. 2006. Identification of the cytochrome P450 monooxygenase that bridges the clavine and ergoline alkaloid pathways. Chembiochem 7, 645-652.

Livak, K.J., Schmittgen, T.D. 2001. Analysis of relative gene expression data using realtime quantitative PCR and the 2(-Delta Delta C(T)) Method. Methods. 25, 402-408. Panaccione, D.G., Johnson, R.D., Wang, J., Young, C.A., Damrongkool, P., Scott, B., Schardl, C.L. 2001. Elimination of ergovaline from a grass-Neotyphodium endophyte symbiosis by genetic modification of the endophyte. Proc Natl Acad Sci USA 98, 1282012825.

Wang , J., Machado , C. , Panaccione, D.G., Tsai, H.-F., and Schardl, C.L. 2004. The determinant step in ergot alkaloid biosynthesis by an endophyte of perennial ryegrass. Fungal Genetics \& Biology 41:189-198. 


\section{FIGURE LEGENDS}

Figure 1: Abundance of mRNA from indicated ergot alkaloid genes in pseudostem, center leaf, outer leaf, flag leaf, inflorescence and dough stage seeds (in the order represented by graphical form) of perennial ryegrass infected with wild-type Neotyphodium sp. Lp1 $(n=3)$. Expression of all tested genes was calculated with the relative comparative Ct method using tefA as the reference gene for normalization.

Figure 2: Abundance of mRNA from indicated genes in pseudostem of perennial ryegrass plant infected with Neotyphodium sp. Lp1 RNAi-1, 2 and 3 transformant strains (A-C respectively). Expression of all tested genes was calculated with the relative comparative Ct method using tefA as the reference gene for normalization.

Figure 3: Abundance of mRNA from indicated genes in pseudostem of perennial ryegrass plant infected with Neotyphodium sp. Lp1 overexpression-1, 2 and 3 transformant strains (A-C respectively) $(n=3)$. Expression of all tested genes was calculated with the relative comparative $\mathrm{Ct}$ method using tefA as the reference gene for normalization. 
Table1: Primers used in real-time quantitative PCR assays

\begin{tabular}{|l|l|}
\hline Primer name & Sequence \\
\hline TQM_tefA_f2 & TGC GCT ATC CTG ATT ATC GCT GCT \\
\hline TQM_tefa_R2 & TTG ATG GCA ACG ATG AGC TGC TTG \\
\hline dmaW_RT(f) & GAG CCA AAC ACA AGC TCC TG \\
\hline dmaW_RT(r) & TTG AGA GGT CCA CCA ACC TTG ACT \\
\hline Lolium EF1-fwd & GCA CAG TTC CAA TGC CAC CAA TCT \\
\hline Lolium EF1-rev & GTC GTC CAT GGT GCC CAT TC \\
\hline easA_RT2_f & TCG AAC TCC ACG GTG CCA AT \\
\hline easA_RT2_r & AGG GAC GAT TTT CCT CAC GCT \\
\hline cloA_RT1_f & GAT GTG AAC ATG GTT TGG GCC \\
\hline cloA_RT1_r & CAA GGG CAT GGC AGT CAA GTT \\
\hline easC_RT2_f & GGC CAA CAT ACG CAC TCA TAC \\
\hline easC_RT2_r & CCA GCA ATG CCT TGT ATG CAG T \\
\hline IpsA_RT2_f & ACG TCG CCT GTA GCT CTC TCA T \\
\hline IpsA_RT2_r & AGT GCC GTC AAC AAG TGG TT \\
\hline easD_RT2_f & ACT GGC CAC GTT GAC GAT ACT \\
\hline easD_RT2_r & \\
\hline
\end{tabular}




\section{FIGURE 1.}

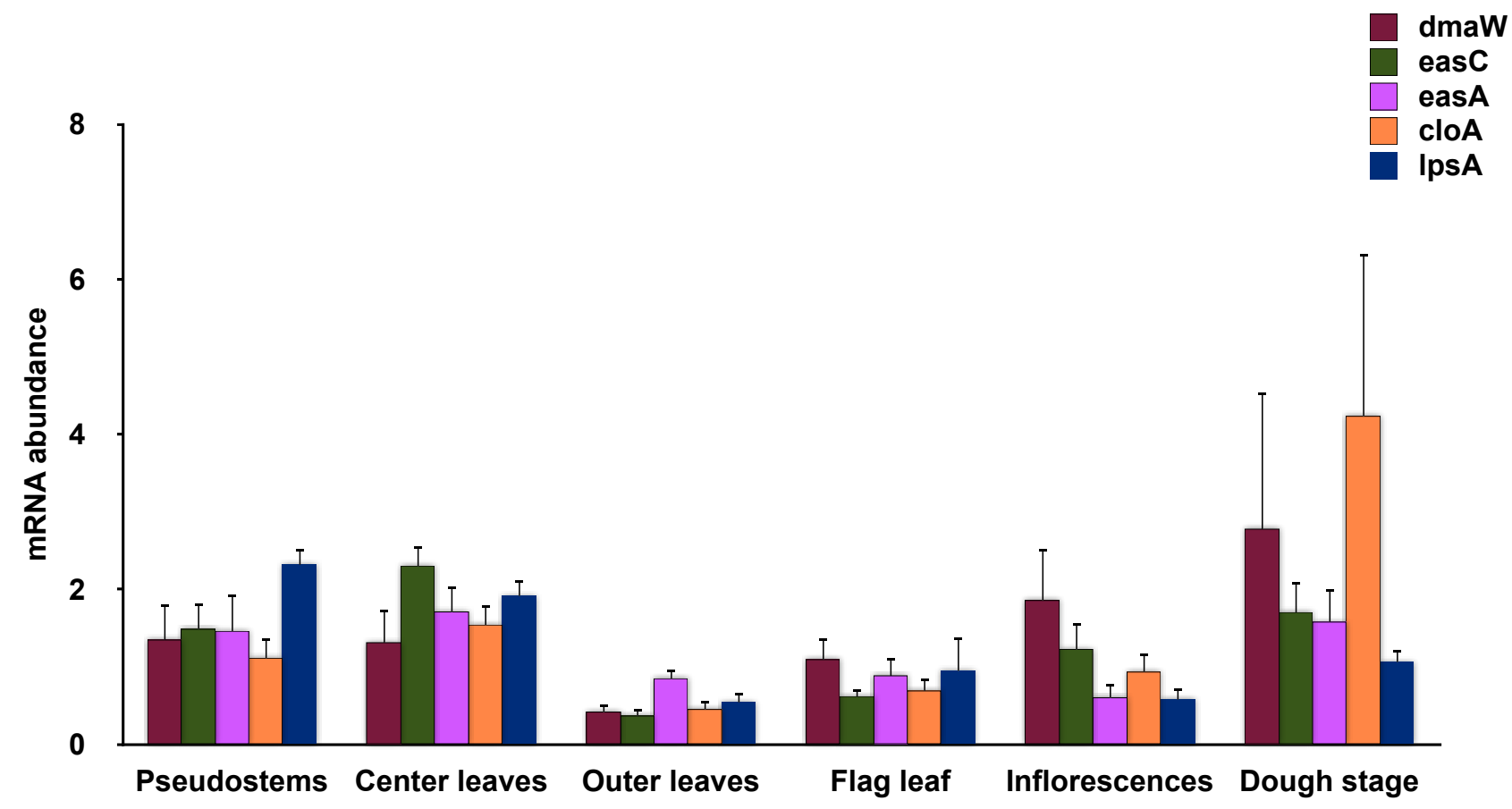




\section{FIGURE 2.}
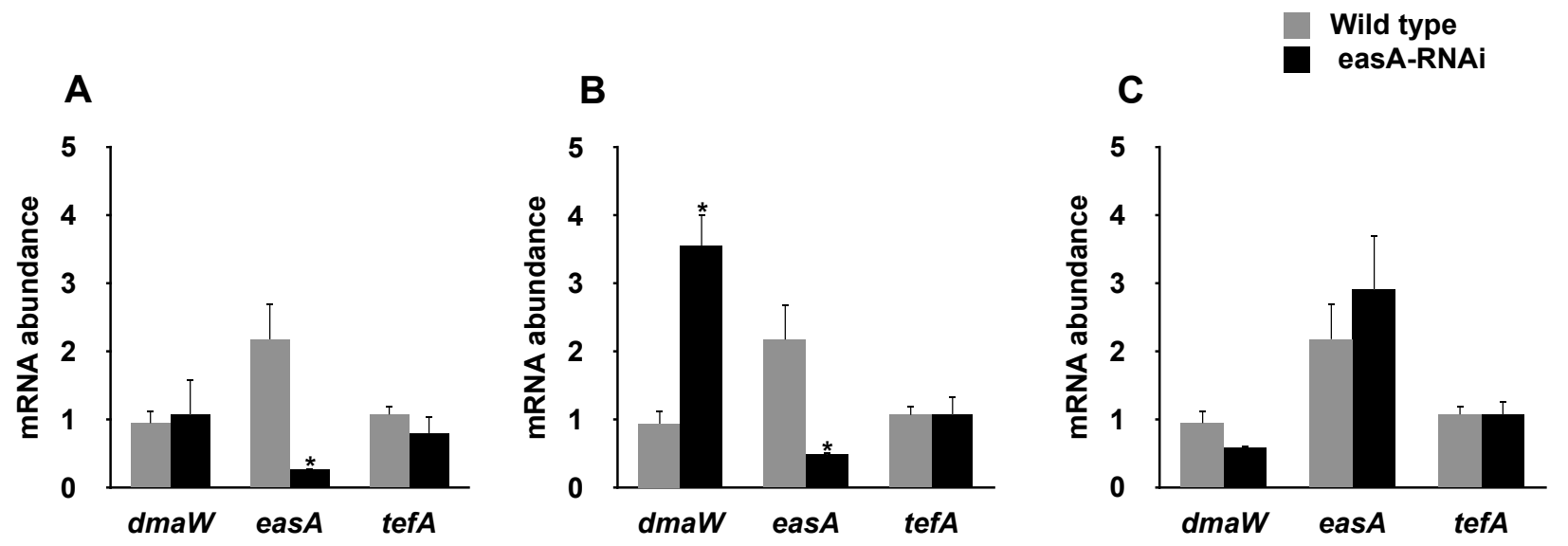


\section{FIGURE 3.}

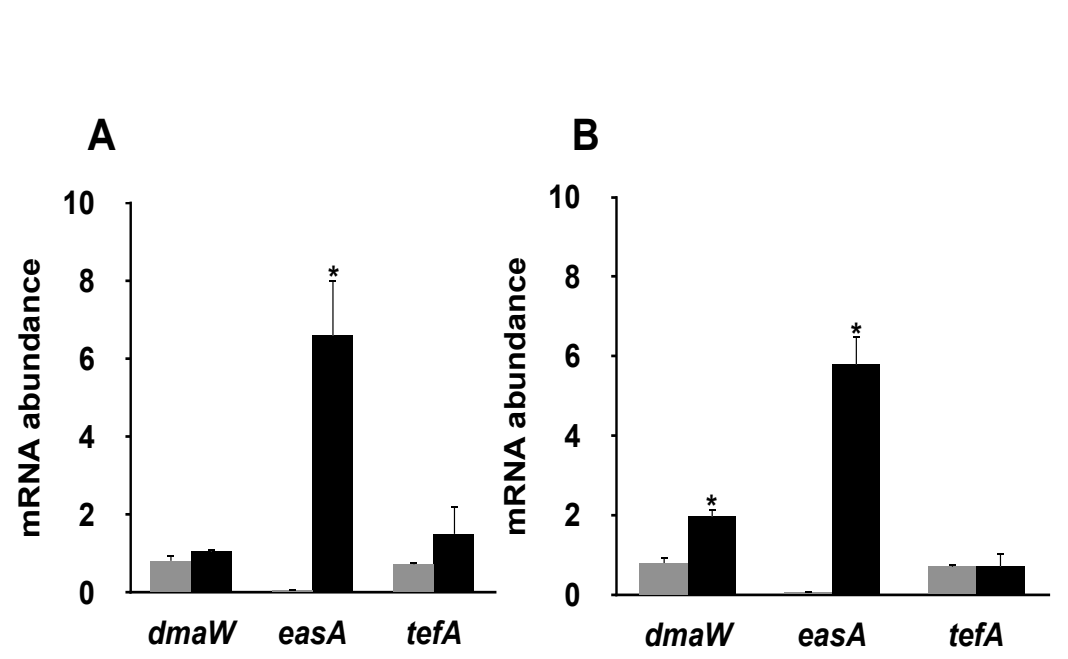

Wild type

easA-Overexpression

C

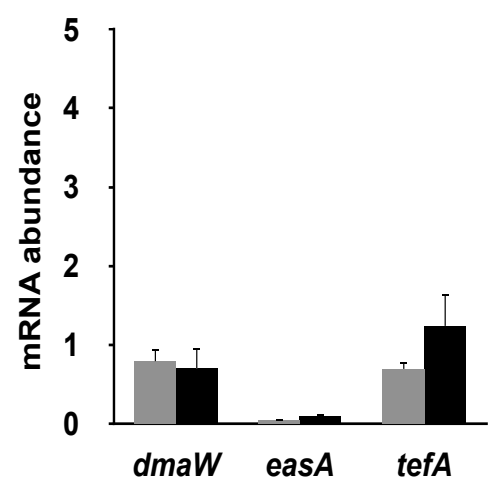




\section{SUMMARY}

I studied the two fungi, Aspergillus fumigatus and Neotyphodium sp. Lp1, in order to investigate potential mechanisms affecting accumulation and transition of alkaloids down the ergot alkaloid pathway. Each fungus provides advantages for addressing different questions related to ergot pathway inefficiency.

Aspergillus fumigatus provides the advantage of having distinct cell types, enabling me to study potential differences in the expression of different ergot alkaloid pathway genes among these cell types. Previous results had demonstrated that ergot alkaloids accumulate in or on conidia (Panaccione and Coyle, 2005; Coyle et al., 2007); however, results from studies of wild type and mutant $A$. fumigatus demonstrated that ergot alkaloids are produced in other cell types that constitute a developing conidiophore. Furthermore, ergot alkaloid profiles from isolated mature conidia and preparations that contained all cell types differed significantly, indicating cell-type specific differences in ergot alkaloid accumulation. GFP expression studies of different ergot alkaloid genes showed that these cell specific differences in alkaloid accumulation are not due to qualitative but rather quantitative cell-type specific differences in the expression of individual pathway genes.

Neotyphodium sp. Lp1, an endophyte of perennial rye grass accumulates different profile of ergot alkaloids in comparison to A. fumigatus and also serves as a good model system to study the pathway inefficiency at tissue specific level of the host plant. I found that ergot alkaloid pathway efficiency varied in different tissues. My data, 
considered along with data provided by S. Florea and C. Schardl (University of Kentucky) indicate that relative mRNA abundance of different ergot alkaloid pathway genes was a significant factor in the different ergot alkaloid profiles observed among different tissues. My attempts to genetically modify pathway efficiency by knocking down and overexpressing easA changed the ergot alkaloid profile of Neotyphodium sp. Lp1. RNAi mediated knock down of easA resulted in higher accumulation of the pathway intermediate chanoclavine and shunt product 6,7-secolysergine and lower accumulation of pathway end product ergovaline. In contrast, overexpression of eas $A$ resulted in higher accumulation of ergovaline and no significant change in the levels of pathway intermediates or shunt products. Therefore, in Neotyphodium sp. Lp1, the abundance of easA mRNA has a significant role in controlling the efficiency in the flow of intermediates down the ergot alkaloid pathway.

This research has demonstrated potential mechanisms involved in the control of ergot alkaloid pathway efficiency and also has developed strategies in controlling pathway efficiency. Manipulation of endophyte ergot alkaloid profiles may have utility in studies of the effects of specific alkaloids in animal toxicosis or in protecting grasses from insects.

\section{REFERENCES}

Coyle, C.M., Kenaley, S.C., Rittenour, W.R., Panaccione, D.G. 2007. Association of ergot alkaloids with conidiation in Aspergillus fumigatus. Mycologia 99, 804-811. Panaccione, D.G., Coyle, C.M. 2005. Abundant respirable ergot alkaloids from the common airborne fungus Aspergillus fumigatus. Appl Environ Microbiol 71, 3106-3111. 


\title{
PRASHANTHI.MULINTI
}

\author{
3360 N.Chatham Road \\ Apt \# I \\ Ellicott city, MD 21042 \\ (304)-685-7916 \\ e-mail: shanthimulinti@gmail.com
}

\section{Education}

Ph.D in Genetics and Developmental Biology - 2011

West Virginia University, Morgantown, WV, USA

Dissertation: "Characterization of ergot alkaloid pathway inefficiency in fungi".

M.S. in Biotechnology - 2006

Osmania University, India

B.Sc. in Biochemistry - 1998

Osmania University, India

\section{Research EXPerience}

\section{----- West Virginia University ------}

Graduate research assistant. Completed four-year research assistantship. Gained experience as an independent researcher and communicated research data into the form of publications and conference proceedings. (Fall 2006 - present).

----- National Institutes of Health ------

Underwent training on TRAC24: DNA Microarray: Principles and application of DNA Microarrays at The Foundation for Advanced Education in the Sciences (FAES), Inc.

\section{ICRISAT, Patancheru, India-----}

Worked as an apprentice on "Development of Transgenic Chickpea (Cicer arietinum. L) for Tolerance to Drought Stress" at Genetic Transformation Lab in International Crops Research Institute for the Semi-Arid Tropics (ICRISAT), Hyderabad, India (May 2005 - December 2005).

\section{Specialized Skills}


Design of RNA interference (RNAi) and overexpression constructs, GFP expression constructs, HPLC, Real-time PCR, PCR, Semi-quantitative PCR, plasmid DNA purification/cloning, southern and western blotting, microarray, yeast two-hybrid analysis, in-situ hybridization, immunohistochemistry, mammalian cell culture, luciferase reporter assays, site-directed mutagenesis, confocal microscopy, recombinant protein production/purification, protein-protein interaction analyses and bioinformatics.

\section{Computer Skills}

JAVA, JSP, ORACLE, Microsoft Office (Word, Excel, Powerpoint, Access), C programming.

\section{Publications}

D. Karlson, K. Nakaminami, K. Thompson, Y. Yang, V. Chaikam and P. Mulinti (2009) Plant cold shock domain proteins: On the tip of an iceberg. In Plant cold hardiness: From the laboratory to the field.

\section{----- Manuscripts in preparation ------}

Prashanthi. Mulinti, N. Allen, C. Coyle and D. G. Panaccione. Spatial expression patterns of ergot alkaloid genes during conidiophore development in Aspergillus fumigatus. (Target journal Eukaryotic cell).

Prashanthi Mulinti, Florea S, Schardl C.L, and Panaccione D.G. Investigation and genetic modification of ergot alkaloid pathway efficiency of Neotyphodium lolii $\times$ Epichloë typhina isolate Lp1 (Neotyphodium sp. Lp1).

\section{Conference proceedings}

Allen, Natalie A, Shanthi Mulinti, and Daniel G. Panaccione. Localization of ergot alkaloid production in the pathogenic fungus Aspergillus fumigatus. REU Symposium 2009.

Prashanthi Mulinti and Daniel G Panaccione. Characterization and genetic modification of ergot alkaloid pathway inefficiency in grass endophytic fungus, Neotyphodium sp. Lp1. Davis college research day 2010, West Virginia University.

Prashanthi Mulinti and Daniel G Panaccione. Spatial expression patterns of ergot alkaloid genes during conidiophore development in Aspergillus fumigatus. Davis college research day 2011, West Virginia University.

\section{FACILITATION OF STUDENT RESEARCH \& LABORATORY EXPERIENCE}

\section{Graduate Students}

Matt Maust- M.S. Agriculture

\section{Undergraduate Students}


Natalie Allen- Biology

JR Ligett- Animal and Nutritional Sciences

Brian Lewis- Biochemistry

\title{
Awards \& Activities
}

Worked as a Programmer/Analyst at ISO NewEngland (Massachusetts).

Secured first prize in the Essay writing competition conducted by the Department of Genetics.

Attended International symposium on "Frontiers in Genetics and Biotechnology Retrospect and Prospect" at Osmania University, Hyderabad.

Attended "Fungal Genetics Conference" at Asilomar, California.

Attended "International Symposium on Fungal Endophyte of Grasses" at Lexington, Kentucky.

\section{References}

\author{
1. Dr. Daniel Panaccione \\ Professor of Mycology \\ Division of Plant and Soil Sciences \\ Davis College of Agriculture, Natural Resources and Design \\ West Virginia University \\ PO Box 6108 \\ Morgantown, WV 26506-6108 \\ (304)-293-8819 \\ danpan@mail.wvu.edu \\ 2. Dr. Jed. H Doelling \\ Associate Professor of Genetics \\ Division of Plant and Soil Sciences \\ Davis College of Agriculture, Natural Resources and Design \\ West Virginia University \\ PO Box 6108 \\ Morgantown, WV 26506-6108 \\ (304) 293-6023 x4347 \\ jed.doelling@mail.wvu.edu
}

3. Dr. Jianbo Yao

Associate Professor of Animal Biotechnology and Genomics

Division of Animal \& Nutritional Sciences

Davis College of Agriculture, Natural Resources and Design

West Virginia University

PO Box 6108

Morgantown, WV 26506-6108

(304)-293-2406 ext. 4444

jianbo.yao@mail.wvu.edu 